\title{
Gene Expression Profiling with Cre-Conditional Pseudorabies Virus Reveals a Subset of Midbrain Neurons That Participate in Reward Circuitry
}

\author{
Lisa E. Pomeranz, ${ }^{1 \star}$ Mats I. Ekstrand, ${ }^{1 \star}$ Kaamashri N. Latcha, ${ }^{2}$ Gregory A. Smith, ${ }^{3}$ Lynn W. Enquist, ${ }^{4,5}$ \\ and Jeffrey M. Friedman ${ }^{1}$ \\ ${ }^{1}$ Laboratory of Molecular Genetics, Howard Hughes Medical Institute, Rockefeller University, New York, New York 10065, 2Department of Biology, \\ Graduate School of Arts and Science, New York University, New York, New York 10003, 32Department of Microbiology-Immunology, Feinberg School of \\ Medicine, Northwestern University, Chicago, Illinois 60611, and ${ }^{4}$ Department of Molecular Biology and ${ }^{5}$ Princeton Neuroscience Institute, Princeton \\ University, Princeton, New Jersey 08544
}

The mesolimbic dopamine pathway receives inputs from numerous regions of the brain as part of a neural system that detects rewarding stimuli and coordinates a behavioral response. The capacity to simultaneously map and molecularly define the components of this complex multisynaptic circuit would thus advance our understanding of the determinants of motivated behavior. To accomplish this, we have constructed pseudorabies virus (PRV) strains in which viral propagation and fluorophore expression are activated only after exposure to Cre recombinase. Once activated in Cre-expressing neurons, the virus serially labels chains of presynaptic neurons. Dual injection of GFP and mCherry tracing viruses simultaneously illuminates nigrostriatal and mesolimbic circuitry and shows no overlap, demonstrating that PRV transmission is confined to synaptically connected neurons. To molecularly profile mesolimbic dopamine neurons and their presynaptic inputs, we injected Cre-conditional GFP virus into the NAc of (anti-GFP) nanobody-L10 transgenic mice and immunoprecipitated translating ribosomes from neurons infected after retrograde tracing. Analysis of purified RNA revealed an enrichment of transcripts expressed in neurons of the dorsal raphe nuclei and lateral hypothalamus that project to the mesolimbic dopamine circuit. These studies identify important inputs to the mesolimbic dopamine pathway and further show that PRV circuitdirected translating ribosome affinity purification can be broadly applied to identify molecularly defined neurons comprising complex, multisynaptic circuits.

Key words: mesolimbic; pseudorabies virus; RNASeq

\section{Significance Statement}

The mesolimbic dopamine circuit integrates signals from key brain regions to detect and respond to rewarding stimuli. To further define this complex multisynaptic circuit, we constructed a panel of Cre recombinase-activated pseudorabies viruses (PRVs) that enabled retrograde tracing of neural inputs that terminate on Cre-expressing neurons. Using these viruses and Retro-TRAP (translating ribosome affinity purification), a previously reported molecular profiling method, we developed a novel technique that provides anatomic as well as molecular information about the neural components of polysynaptic circuits. We refer to this new method as PRV-Circuit-TRAP (PRV circuit-directed TRAP). Using it, we have identified major projections to the mesolimbic dopamine circuit from the lateral hypothalamus and dorsal raphe nucleus and defined a discrete subset of transcripts expressed in these projecting neurons, which will allow further characterization of this important pathway. Moreover, the method we report is general and can be applied to the study of other neural circuits.

\section{Introduction}

Neuroanatomical tracers have proven invaluable for visualizing and defining complex neural circuits. While some viral tracers such as adenovirus and adenoassociated virus label only primary

Received Oct. 14, 2016; revised Feb. 6, 2017; accepted Feb. $27,2017$.

Author contributions: L.E.P., M.I.E., and J.M.F. designed research; L.E.P., M.I.E., and K.N.L. performed research; L.E.P., M.I.E., G.A.S., L.E., and J.M.F. contributed unpublished reagents/analytic tools; L.E.P., M.I.E., and J.M.F. analyzed data; L.E.P., M.I.E., and J.M.F. wrote the paper. neurons, other viruses, including pseudorabies virus (PRV) are transmitted across synapses and can be used to define the polysynaptic connections of infected neurons. Additional viruses in

This work was supported by the JPB Foundation, the National Institute of Drug and Alcohol Abuse (Grant R01 DA018799), and the National Institutes of Health (Grant R01 Al056346 to G.A.S., Grant R01 NS060699 to L.W.E.). We thank Audrey Liu for her contributions to the cloning of the PRV-Bartha genome and to Sarah A. Stern for helpful discussion and her thoughtful comments on this manuscript. We are grateful to Nicholas Socci for his analysis of our anatomical tracing results and hierarchical spread of PRV. 
the subfamily Alphaherpesvirinae (e.g., herpes simplex virus/ HSV) and some Rhabdoviridae such as vesicular stomatitis virus and rabies virus (RV) are also capable of multisynaptic spread within the mammalian nervous system, and all recapitulate the neural projections identified using other methods (Kelly and Strick, 2000; Pomeranz et al., 2005; Wickersham et al., 2007a,b; Ekstrand et al., 2008; Beier et al., 2011; Lanciego and Wouterlood, 2011; Ugolini, 2011; Beier et al., 2013, 2015; Card and Enquist, 2014; Mundell et al., 2015).

PRV-Bartha is an attenuated vaccine strain of PRV that spreads retrogradely along chains of synaptically connected neurons (Pickard et al., 2002). To trace the presynaptic connectivity of genetically defined neurons, our laboratory previously made a conditional PRV-Bartha in which viral replication and propagation depend on the expression of the Cre-recombinase in defined neurons. Specifically, PRV-Ba2001 used a standard lox-stop-lox cassette to control Cre dependent expression of the essential PRV thymidine kinase (tk) gene. Retrograde spread of the virus was used to map neural inputs to Cre-expressing neurons in a hypothalamic feeding center (DeFalco et al., 2001). Similar approaches were used to map anterograde circuitry with modified HSV (Lo and Anderson, 2011; Anthony et al., 2014) and to map monosynaptically connected neurons using defective RV strains (Wickersham et al., 2007b). Since its publication, PRV-Ba2001 has been used to map presynaptic inputs to defined neural populations as well as in other instances to show that neighboring circuits were not synaptically connected (Yoon et al., 2005; Campbell and Herbison, 2007; Braz et al., 2009). However, we found that the use of PRV-Ba2001 required testing a range of viral titers in animals to define an inoculum that did not lead to infection of neurons in the absence of Cre.

For the present study, we developed a nonleaky PRV retrograde transsynaptic tracer in which the activation of both PRV tk and a fluorescent reporter are entirely dependent on Cre expression. This was accomplished by inserting a synthetic intron into the PRV tk gene and then inverting one of the exons with a FLEx switch that can be resolved via Cre recombination. The resulting virus, PRV-Introvert, showed no background at all titers that were tested. Simultaneous tracing of the separate mesolimbic and nigrostriatal circuitry was accomplished by producing individual viruses that conditionally express either GFP or mCherry.

We previously reported retrograde translating ribosome affinity purification (Retro-TRAP), a technique to molecularly profile neurons based on their pattern of projections (Ekstrand et al., 2014). Retro-TRAP relies on viral expression of GFP to precipitate polysomes from neurons in transgenic mice that express an anti-GFP nanobody fused to the Rpl10a ribosomal protein (SYN-NBL10). However Retro-TRAP, which uses a nonreplicating canine adenovirus (CAV), can only be used to profile first order neurons projecting to specific sites and thus was not capable of identifying the neural components of polysynaptic circuits.

In this report, we show that retrograde tracing using these modified nonleaky PRV strains in combination with translating ribosome affinity purification enables both anatomical mapping and molecular profiling of polysynaptic inputs to molecularly

*L.E.P. and M.I.E. contributed equally to this work.

The authors declare no competing financial interests.

Correspondence should be addressed to Jeffrey M. Friedman Laboratory of Molecular Genetics, Howard Hughes Medical Institute, The Rockefeller University, 1230 York Avenue, New York, NY 10065. E-mail: friedj@mail.rockefeller.edu.

M. I. Ekstrand's present address: Illumina Inc., 5200 Illumina Way, San Diego, CA 92122.

DOI:10.1523/JNEUROSCI.3193-16.2017

Copyright $\odot 2017$ the authors $\quad 0270-6474 / 17 / 374129-17 \$ 15.00 / 0$ defined neural populations. We used this approach to identify neurons in both the midbrain and hypothalamus that project to the mesolimbic dopamine circuit. Finally, we identified a panel of molecular markers enriched in the lateral hypothalamus (LH) and the dorsal raphe nucleus (DRN) in neurons that project both directly and indirectly to the mesolimbic dopamine circuit. In addition to defining neural components of reward circuitry, these data validate PRV-Circuit-TRAP as a general method that can be used to anatomically and molecularly define the cellular components of complex neural circuits.

\section{Materials and Methods \\ Mice}

All experiments performed in these studies were approved by the Rockefeller University Institutional Animal Care and Use Committee and were in accordance with the National institute of Health guidelines. DAT-Cre transgenic mice (Ekstrand et al., 2007) were kindly provided by N.-G. Larsson (Karolinska Institute, Solna, Sweden). SYN-NBL10 mice were made at the Rockefeller University as described previously (Ekstrand et al., 2014). Male and female wild-type C57Bl6 (The Jackson Laboratory, RRID:IMSR_JAX:000664), DAT-Cre, and SYN-NBL10 mice were between 10-20 weeks at the time of surgery. All mice were group housed on a $12 \mathrm{~h}$ light/dark cycle with ad libitum access to water and standard mouse chow (PicoLab Rodent Diet).

\section{Viruses}

Bartha-BAC (PRV-GS420/pBartha2 bacterial artificial chromosome) is the parental virus for all tracing strains used in this paper and was made by G. Smith, A. Liu, and L. Enquist at Princeton University. Virus stocks were grown and tittered in PK15 cells. Nucleocapsid DNA from a plaque purified isolate of PRV-Bartha was cotransfected with targeting vector pGS339 to make the pGS420 BAC by allelic exchange as described previously (Smith and Enquist, 2000). Subsequent tracing viruses were derived from the pGS420 BAC via recombineering in SW102 cells (Warming et al., 2005). PRV-TK $\Delta$ galK was made by replacing the UL23/tk open reading frame (ORF) with the galactokinase gene (galK) via recombineering using the primer set otkgalK5' (GGAAGCAGAACGGCAGCCTGAGCGAGGAGGACGCGGCCCTCGTCACGGCGGAATTCCCTGTTGACAATTAATCATCGGCA) and otkgalK3' (AGCGGCAGCAGCTTGGCCACGAGCGCGTCCATCGCCCACGCGTGCACCTCGAATTCTCAGCACTGTCCTGCTCCTT) to insert galK. PRV- $\Delta$ TK was published previously as PRV-GFP in the study by Chaudhury et al. (2013). To make PRV- $\Delta \mathrm{TK}$, annealed oligos $\Delta$ TKUltfor (GGAAGCAGAACGGCAGCCTGAGCGAGGAGGACGCGGCCCTCGTCACGGCGGAGGTGCAC GCGTGGGCGATGGACGCGCTCGTGGCCAAGCTGCTGCCGCT) and $\Delta$ TKUltrev (AGCGGCAGCAGCTTGGCCACGAGCGCGTCCATCGC CCACGCGTGCACCTCCGCCGTGACGAGGGCCGCGTCCTCCTC GCTCAGGCTGCCGTTCTGCTTCC) to replace galK and $545 \mathrm{bp}$ of the TK coding sequence followed by growth in the presence of 2-deoxy-galactose (DOG) to select against galK-containing BACs to make PRV- $\Delta$ TK. PRVIntrovert, PRV-Introvert-GFP, and PRV-Introvert-mCherry were made in multiple recombineering steps. PRV-LSL-TK was made in two steps. First galK was amplified using the primer set gG $\Delta$ galKfor (CGCGCATCG ACACCCTGATGGAGTACGCCCTCGTGAACGCCAGCCTCGTGCT GCAGCCTGTTGACAATTAATCATCGGCA) and gGAgalKrev (TCGCC AAAGACGAGCACGACGATGTACAGGCCGGCGTCGTACAGCCCGG GCTCAGCACTGTCCTGCTCCTT) and inserted into the US4/gG locus of PRV- $\Delta$ TK by recombineering to make PRV $\Delta$ TK/gG $\Delta$ galK. GalK was subsequently replaced in PRV $\Delta \mathrm{TK} / \mathrm{gG} \Delta$ galK by recombineering with a 5612 bp fragment containing CMV $>$ LSL $>$ mCherry-ires-PRV (the CMV immediate early promoter from pEGFP-N1, the loxP-stop-loxP cassette, and mCherry-ires-PRVTK) with $500 \mathrm{bp}$ gG flank on either side to make PRV-LSL-TK. PRV-Inverted-TK was made by recombineering between a 4197 bp fragment containing CMV>DIO mCherry-iresPRVTK (double-floxed inverted mCherry-ires-PRVtk) with $500 \mathrm{bp}$ of gG flank on either side and PRV $\Delta$ TK/gG $\Delta$ galK and growth in the presence of DOG. 
Stereotaxic surgeries

DAT-Cre, DAT-CreXSYN-NBL10 transgenic, or wild-type mice 10-20 weeks of age were induced and maintained on isoflurane anesthesia before being injected (either bilaterally or unilaterally as noted in figures and text) with $0.5 \mu \mathrm{l}$ PRV in the nucleus accumbens (NAc) shell (coordinates, $\pm 1.44 \mathrm{~mm} \mathrm{M} / \mathrm{L},+1.35 \mathrm{~mm} \mathrm{~A} / \mathrm{P},-4.2 \mathrm{~mm} \mathrm{D} / \mathrm{V}$ at a $6^{\circ}$ angle) or caudate-putamen (coordinates, $+1.5 \mathrm{~mm} \mathrm{M} / \mathrm{L},+0.5 \mathrm{~mm} \mathrm{~A} / \mathrm{P},-2.5$ $\mathrm{mm} \mathrm{D} / \mathrm{V}) . \mathrm{M} / \mathrm{L}$ and $\mathrm{A} / \mathrm{P}$ coordinates are relative to Bregma, and $\mathrm{D} / \mathrm{V}$ coordinates are relative to the pial surface. After viral injections, the needle was left in place for $10 \mathrm{~min}$ before slowly retracting. The skin was closed with a surgical clip.

\section{Immunohistochemistry and imaging}

Mice were anesthetized with isoflurane and killed by cardiac perfusion with PBS $12-15 \mathrm{ml} / \mathrm{min}$ for $5 \mathrm{~min}$ followed by $10 \%$ formalin for $10 \mathrm{~min}$. Brains were removed and incubated in $10 \%$ formalin at $4^{\circ} \mathrm{C}$ overnight followed by PBS. Fifty micrometer sections were obtained on a Leica vibratome and processed for immunohistochemistry. Primary antibodies used for immunohistochemistry were chicken anti-GFP (Abcam, catalog \#ab13970, RRID: AB_300798, 1:1000), rabbit anti-PRV (Thermo Fisher Scientific, catalog \#PA1-081, RRID:AB_325805, 1:250), rabbit anti-tyrosine hydroxylase (TH; Pel-Freeze, catalog \#P40101-0, RRID:AB_461064, 1:1000) or chicken anti-TH (Aves Labs, catalog \#TYH, RRID:AB_10013440, 1:1000), rabbit antihemagglutinin (HA; Invitrogen, catalog \#71-5500, RRID:AB_2533988, 1:1000), rabbit anti-Tph2 (Novus Biologicals, catalog \#NB100-74555, RRID: AB_1049988, 1:500), rabbit anti-Mch (Phoenix Pharmaceuticals, catalog \#G-070-47, RRID:AB_10013632, 1:1000), rabbit anti-orexin/hypocretin (Hcrt; Phoenix Pharmaceuticals, catalog \#H-003-30, RRID:AB_2315019 1:1000), rabbit anti-cocaine- and amphetamine-regulated transcript (Cart; Phoenix Pharmaceuticals, catalog \#H-003-62, RRID:AB_2313614, 1:500), rabbit anti-Galanin (Peninsula Laboratories, catalog \#T-4334.0050, RRID: AB_518348, 1:500), and rabbit anti-Pomc (Phoenix Pharmaceuticals, cata$\log$ \#H-029-30, RRID:AB_2307442, 1:1000). Secondary antibodies were conjugated to Alexa Fluor 488 or 594 (Invitrogen). Stained sections were floated in PBS onto slides and allowed to dry slightly before application of Fluoromount-G mounting medium with DAPI (Southern Biotech, catalog \#0100-02) or without DAPI (catalog \#0100-02), as noted in figures. Images were acquired on a Zeiss Inverted LSM 780 laser scanning confocal microscope. Scale bars were added to .lsm or .tiff images using FIJI/ImageJ.

\section{$P R V$-directed translational ribosome affinity purification}

Immunoprecipitation of NBL10 ribosomes and associated RNA was performed as follows (Ekstrand et al., 2014). A more detailed protocol is available in the study by Nectow et al. (2015).

Preparation of beads. Before preparing homogenates, Streptavidin MyOne T1 Dynabeads (300 $\mu$ l per IP, Invitrogen) were washed twice on a magnetic rack with PBS and loaded with biotinylated Protein L (120 mg, Thermo Fisher Scientific) for $35 \mathrm{~min}$ at room temperature. The Protein L loaded beads were blocked by five washes in PBS with 3\% IgG-free and protease-free BSA (Jackson ImmunoResearch). After the final block was removed, beads were resuspended in wash buffer 1 (10 mM HEPES, pH 7.4, $150 \mathrm{~mm} \mathrm{KCl,} 5 \mathrm{~mm} \mathrm{MgCl}_{2}, 1 \% \mathrm{NP}-40$ ) with anti-GFP mouse monoclonal antibodies (50 $\mu \mathrm{g}$ each of clones 19C8 and 19F7; Doyle et al., 2008) and incubated with rotation for $35 \mathrm{~min}$ at room temperature.

Dissection, homogenization, and preparation of CNS lysate. Three days after bilateral NAc injection with $500 \mathrm{nl}$ PRV-Introvert-GFP $\left(\sim 6.5 \times 10^{5}\right.$ $\mathrm{pfu} /$ per side), mice were killed by cervical dislocation and brains were rapidly dissected on ice in dissection buffer ( $1 \times$ HBSS, 2.5 mM HEPES, pH 7.4, 35 mm glucose, $4 \mathrm{~mm} \mathrm{NaHCO} 3$ ) with $100 \mathrm{mg} / \mathrm{ml}$ cycloheximide (Sigma). A 4 $\mathrm{mm}$ slice was made approximately covering the region from 0 to $4 \mathrm{~mm}$ posterior to Bregma, and lateral and dorsal portions were removed to isolate hypothalamus and midbrain. Sections were pooled into three groups of three infected mice per group (input sample). As a control, parallel dissections were performed from three groups of two wild-type mice that had not undergone stereotaxic surgery or been exposed to virus (control sample). The sections from each group were combined, transferred to a glass homogenizer (Kimble Kontes 20) and homogenized in $1.5 \mathrm{ml}$ ice-cold homogenization buffer (10 mM HEPES, pH 7.4, $150 \mathrm{~mm} \mathrm{KCl,} 5 \mathrm{~mm} \mathrm{MgCl}_{2}$ ) with 0.5 mм DTT (Sigma), 80 U/ml Rnasin Plus (Promega), 40 U/ml Superase-In
(Life Technologies), $100 \mathrm{mg} / \mathrm{ml}$ cycloheximide, protease inhibitor cocktail (Roche), and $100 \mathrm{ng} / \mathrm{ml}$ recombinant nanobody protein (GFP-Trap protein, ChromoTek) 3 times at low speed ( $250 \mathrm{rpm})$ and 10 times at high speed (750 $\mathrm{rpm})$ on a variable-speed homogenizer (Glas-Col) at $4^{\circ} \mathrm{C}$. Homogenates were transferred to microcentrifuge tubes and clarified at $2000 \times g$ for 10 $\min$ at $4^{\circ} \mathrm{C}$. One hundred forty microliters each of $10 \%$ IGEPAL CA-630 (NP-40; Sigma) and 1,2-diheptanoyl-sn-glycero-3-phospho-choline (100 $\mathrm{mg} / 0.69 \mathrm{ml}$; Avanti Polar Lipids) were added to the supernatant. The solutions were mixed and centrifuged again at $17,000 \times g$ for $15 \mathrm{~min}$ at $4^{\circ} \mathrm{C}$. The resulting supernatants were transferred to new tubes and a $50 \mu \mathrm{l}$ aliquot of cleared lysate was combined with an equal volume of Agilent Lysis Buffer (Absolutely RNA Nanoprep Kit) with $\beta$-mercaptoethanol (input sample) and stored at $-80^{\circ}$. The remaining cleared lysate was used for immunoprecipitation. Input RNA and control RNA were purified from infected and uninfected supernatants, respectively, using the Absolutely RNA Nanoprep Kit (Agilent Technologies).

Immunoprecipitation. Beads were washed twice in wash buffer 2 (10 mм HEPES, pH 7.4, 350 mм KCl, 5 mм $\mathrm{MgCl}_{2}, 1 \%$ NP-40, 0.5 mм DTT, $80 \mathrm{U} / \mathrm{ml}$ Rnasin Plus, and $100 \mathrm{mg} / \mathrm{ml}$ cycloheximide) before the cleared brain lysates were added. The immunoprecipitation was allowed to run at $4^{\circ} \mathrm{C}$ for $40 \mathrm{~min}$. Beads were washed four times with wash buffer 2 , and the beads were moved to a new tube before removing the fourth wash solution. After the final wash, RNA was eluted by adding $100 \mu$ l Agilent Lysis Buffer and purified using the Absolutely RNA Nanoprep Kit (Agilent Technologies).

\section{Analysis and sequencing of RNA}

RNA yield (nanograms per microliter) and quality [RNA integrity number (RIN)] were quantified using an Agilent 2100 Bioanalyzer. Total immunoprecipitated (IP) RNA yield for each of the three groups was between 10 and $40 \mathrm{ng}$, while the input sample RNA yield ranged from 16 to $48 \mathrm{ng} / \mu$ l. RIN values for all IP samples used were 9.4 or greater, those for input samples were 8.5 or greater, and those for control samples were 7.3 or greater. Libraries for RNAseq require a minimum of $5 \mathrm{ng}$ RNA and were prepared with oligo dT priming using the SMARTer Ultra Low Input RNA Kit (Clontech) and sequenced on an Illumina HiSeq 2000 using 100 base single reads. Sample reads in FASTQ format were uploaded to the Illumina BaseSpace platform, filtered, and trimmed using Bowtie (version 0.12.9). Reads $>35$ bases were aligned to the mouse mm10 genomic assembly using TopHat (version 2.0.7). Transcript abundance was quantified and differential expression and $q$ values were calculated using TopHat and Cufflinks (version 2.1.1; Trapnell et al., 2013).

To identify neuronal markers that are enriched after retrograde tracing with PRV-Introvert-GFP, we needed to account for the effects on gene expression caused by PRV infection (Ray and Enquist, 2004; Paulus et al., 2006; Flori et al., 2008; Szpara et al., 2010; Harkness et al., 2014; Oláh et al., 2015; Hu et al., 2016). We calculated the change in gene expression resulting from PRV infection as the ratio of control (uninfected) RNA to input (infected) RNA in fragments per kilobase of transcript per million mapped reads (FPKM). A total of 722 genes were significantly upregulated (control RNA/input RNA $<0.5, q<0.05$ ), and 161 genes were significantly downregulated (control RNA/input RNA $>2.0, q<0.05$ ) in infected CNS tissue. To account for the effect of PRV infection on gene expression, a weighted enrichment value was calculated by multiplying each enrichment value by a correction ratio. The formula for weighted enrichment for each gene was weighted enrichment $=$ enrichment $\times$ correction ratio or weighted enrichment $=($ FPKM IP RNA/FPKM input RNA)* (FPKM control RNA/FPKM input RNA).

The correction ratio increases the enrichment value of genes that are downregulated during PRV infection so that important neuronal markers whose expression is reduced during infection will not be overlooked. Nevertheless, we found that weighting the enrichment values had minimal effect on the ranking of the top 60 enriched genes (see Table 2). Scatter plots of differential expression were produced using GraphPad Prism software. Of $\sim 23,000$ genes that could be detected by RNA sequencing, 2408 transcripts were differentially expressed between our IP and input samples ( $q$ value $<0.05$ ), and 404 of these genes $(1.7 \%)$ exhibited twofold or greater enrichment. Note that RNA sequencing data are 
available through NCBI GEO (http://www.ncbi.nlm.nih.gov/geo, Accession\# GSE95234).

\section{Quantitative real-time PCR}

For quantitative real-time PCR, cDNA was prepared using a QuantiTect Reverse Transcription kit (QIAGEN) followed by qPCR with Taqman Fast Advanced Master Mix on a 7500 Fast Real-Time PCR System (Applied Biosciences). For qPCR, all Taqman values were normalized to ribosomal protein Rpl23. Paired Student's $t$ tests were performed using GraphPad Prism to compare IP and input RNA.

\section{Results}

Elimination of leaky reporter gene expression and tracing in a Cre-dependent PRV retrotracer

Our group and others have previously used Cre recombination as an on/off switch to activate viral thymidine kinase (TK) and propagation of herpes-based neuroanatomical tracers (DeFalco et al., 2001; Yoon et al., 2005; Lo and Anderson, 2011). PRV TK is required for viral replication in postmitotic cells such as neurons (but is not required in transformed cell lines). Thus, viral infections of neurons with $\mathrm{tk}^{-}$viruses are not productive. In a previous study from our group, PRV tk expression was controlled by a lox-stop-lox cassette placed upstream of the tk coding sequence (DeFalco et al., 2001). However, we found that PRV tk expression in the absence of Cre was sometimes seen when high viral titers were injected into the CNS and meticulous virus titering in vivo was required to avoid Cre-independent PRV tracing. We thus set out to further limit PRV tk expression in the absence of Cre to eliminate any possible background.

Toward this end, we compared PRV tk expression in a virus harboring an internal deletion in the PRV tk allele $(\Delta T K)$ with three new and alternative strategies for conferring nonleaky Creconditional control over PRV tk expression. These included the use of a lox-flanked transcriptional stop sequence (LSL-TK) similar to that used in Ba2001, a PRV tk that was inverted between two inverted lox sites (Inverted-TK) in which Cre repairs the inversion, and finally a partial inversion combined with a synthetic intron within the PRV tk gene (Introvert; Fig. 1A). Of these, Introvert-TK was the only construct that completely silenced PRV tk expression in the absence of Cre. In this approach, the PRV tk reading frame was interrupted by the insertion of a synthetic intron with the second exon of TK (Fig. 1A, TK-2) placed in the opposite orientation of the first exon (TK-1). Two sets of lox sites were placed on either side of the second exon (TK-2) such that Cre-mediated recombination inverts this exon and restores correct PRV tk translation after splicing. In the absence of recombination, the reading frame is disrupted by the inverted, out-offrame second exon. After recombination, the remaining lox site lies within an intron sequence and are spliced out of the mature message. Because PRV tk expression relies on both intron-directed splicing and Cre-inversion, we refer to this virus as PRV-Introvert.

We confirmed the absence of TK expression in the unrecombined construct in vitro and in vivo. Tk activity in vitro was quantitated by titering PRV grown in the presence of $1-\beta$-Darabinofuranosylthymine (AraT), a substrate of the viral thymidine kinase that inhibits viral DNA replication (Gentry and Aswell, 1975). Expression of tk leads to lethality of cells grown in AraT. TK activity was not detected in cultured cells infected with PRV-Introvert while TK activity was restored in PRV-Introvert stocks grown in Creexpressing cells (Fig. $1 B$ ).

We next tested the different viral strains in vivo. Injection of PRV-Bartha-BAC into the NAc is uniformly lethal to wild-type mice, and $100 \%$ die within $5 \mathrm{~d}$ (Fig. 1C). Mice injected with TK null virus do not develop symptoms of infection for the duration of the experiment ( $>2$ weeks), indicating that functional TK is required for the lethal effects of PRV infection. Similar to the case with TK null virus, wild-type animals injected with PRVIntrovert survive and do not develop symptoms of viral infection (Fig. 1C, Introvert + wt). In contrast, the aforementioned PRV tk mutants showed lethality in wild-type animals though at significantly lower levels compared with a wild-type PRV-Bartha-BAC. Overall, these data confirm that that PRV-Introvert will not infect neurons in the absence of Cre expression.

We next confirmed that PRV-introvert can only be activated in the presence of Cre. We tested this by infecting the dense field of terminals from dopaminergic ventral tegmental area (VTA) neurons that project to the NAc originating from the VTA. The VTA and NAc are sufficiently distant in the mouse brain $(>3.0 \mathrm{~mm})$ to allow infection of nerve terminals without simultaneously infecting cell bodies (Franklin and Paxinos, 2008). In DAT-Cre mice, Cre recombinase expression is directed by the dopamine transporter promoter (Ekstrand et al., 2007; Lammel et al., 2015). Thus, injection of PRVIntrovert into the NAc of DAT-Cre mice provides an opportunity to map the upstream inputs to this mesolimbic pathway. We found that injection of PRV-Introvert into the NAc of DAT-Cre mice resulted in GFP expression in the cell bodies of dopaminergic neurons in the VTA as well as in structures that send neural inputs to the VTA and NAc. Furthermore, injection of PRV-Introvert into the NAc of DAT Cre mice was lethal in all of the infected DAT-Cre mice, with all showing neurological symptoms followed by death within 5 days (Fig. 1C, Introvert + DAT-Cre). As above, PRV-Introvert injection into the NAc has no detectable effect on the health of wild-type mice (Fig. 1C, Introvert $+w t$ ), demonstrating the requirement for Cre recombinase after PRV-Introvert infection in mice.

Because GFP expression in PRV-Introvert was constitutive and not conditional on Cre expression, all neurons at the site of injection take up the injected PRV and express GFP even without viral activation. For example, wild-type mice injected with PRVIntrovert in the NAc show GFP expression at the injection site and also in areas that send direct projections to the NAc such as the insular cortex with a few GFP+ neurons also observed in the amygdala (Am) and $\mathrm{LH}($ Fig. $1 D, 1,3,5,7)$. In contrast, injection of PRV-Introvert into DAT-Cre mice led to extensive GFP expression in polysynaptic inputs to VTA dopamine neurons at multiple loci not seen in wild-type animals. The widespread GFP staining in DAT-Cre is seen because Cre activation of PRV is followed by viral replication and retrograde transynaptic spread of infection to numerous other sites (Fig. 1D, 2, 4, 6, 8). While these studies validated the capacity of PRV-Introvert to confer tight control over viral infection, this strategy was not optimal for identifying synaptically connected neurons owing to constitutive GFP expression in local and distant neurons even in the absence of Cre.

\section{Cre-mediated control over GFP expression in PRV-Introvert-GFP}

We next developed a version of PRV-Introvert in which both PRV tk (viral replication) and GFP expression were dependent on the expression of Cre-recombinase. In this strain, referred to PRV-Introvert-GFP, a $2 \mathrm{~A}$ self-cleaving peptide (Donnelly et al., 2001) was placed between PRV tk and GFP with introns introduced into both genes. In the nonrecombined configuration, the second exon of PRV tk (TK-2) together with the 2A-linked first GFP exon (GFP-1) are placed in a reverse orientation, thus disrupting both open reading frames (Fig. 2A, Introvert-GFP). As with PRV-Introvert, Cre recombination flips matching lox sites 
A i. Bartha-BAC

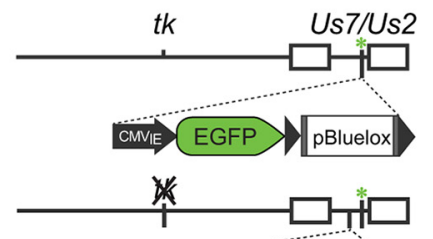

ii. $\Delta \mathrm{TK}$

iii. LSL-TK

iv. Inverted-TK

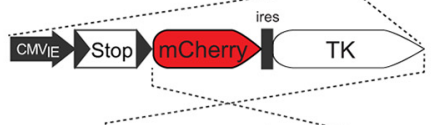

v. Introvert

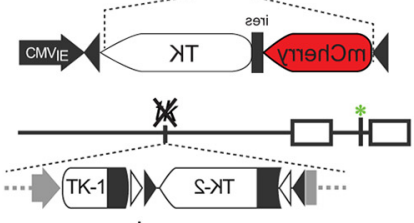

$\downarrow$ Cre recombination

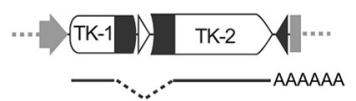

B

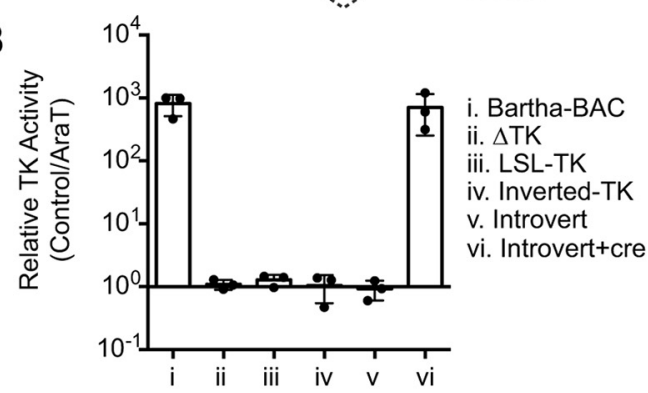

C

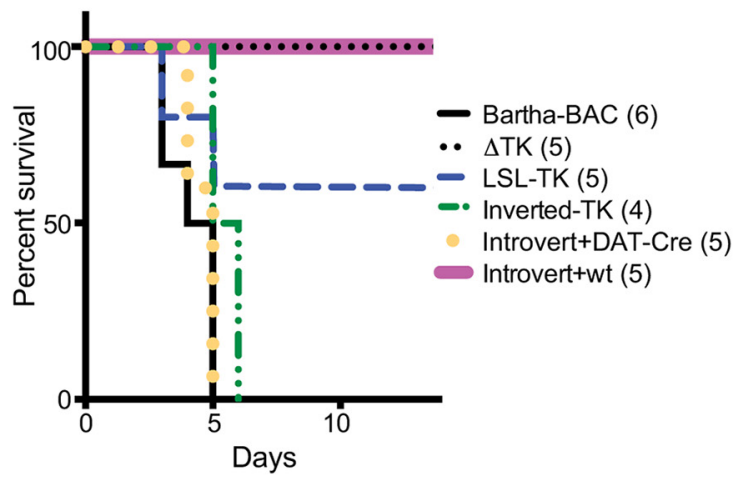

D

\section{NAc injection (PRV-Introvert)}

wild type DAT-Cre
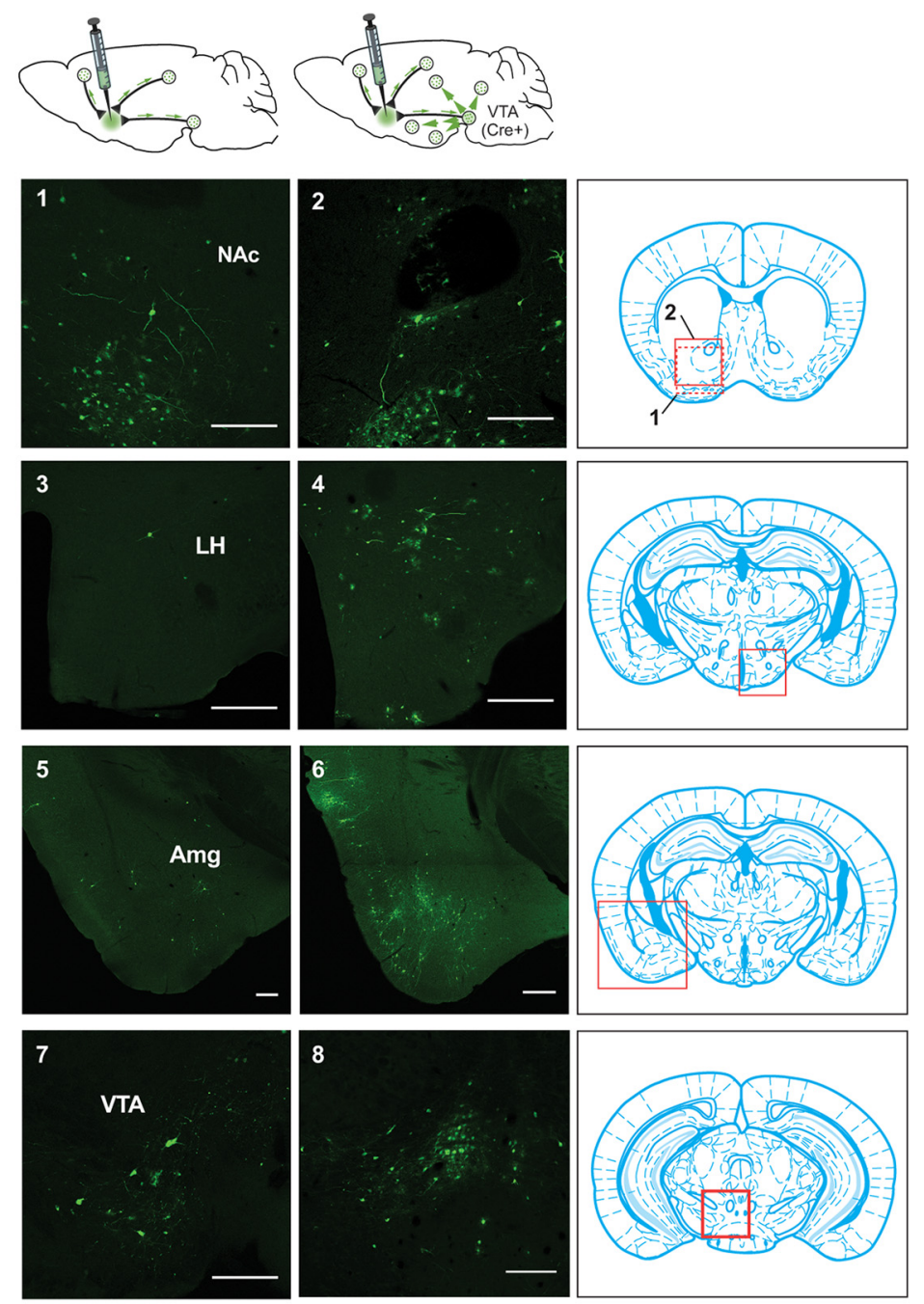

Figure 1. Cre-conditional retrograde tracing with PRV-Introvert. $A$, Schematic of PRV-Introvert construction. Bartha-BAC, the parent of PRV-Introvert, expresses full length PRV tk from its native promoter (i). EGFP (green asterisk) and the sequence for maintenance as a bacterial artificial chromosome (pBluelox; Smith and Enquist, 2000) are inserted into the Us $7 /$ S 2 locus. $\Delta$ TKhas a deletion of the PRV tk gene (ii). In LSL-TK, PRV tk is controlled by a lox-stop-lox cassette between the CMV immediate early (IE) promoter and mCherry-ires-tk, all of which is inserted into the PRV gG/U 4 locus (iii). In Inverted-tk, mCherry-ires-tk is reversed between two lox sites (iv). In PRV-Introvert, the PRV tk gene is split into 5' and 3' ends between two sets of inverted lox sites. Cre recombination flips the $3^{\prime}$ end of PRV tk into the same orientation as the $5^{\prime}$ end and removes two lox sites. The single lox site that remains within the PRV tk transcript is removed by splicing. Open triangles represent loxN sites while lox2722 sites are represented by shaded triangles (v). $\boldsymbol{B}$, TK activity of parental strain (Bartha-BAC) and mutants. Virus stocks were titered in the presence or absence of AraT, a nucleoside analog that inhibits viral replication in the presence of PRV TK. TK activity is measured as the ratio of the number of plaques without AraT/ with AraT. C, Kaplan-Meier curve showing mouse survival after injection of PRV into the NAc. Bartha-BAC, $\triangle T$ TK, LSL-TK, Inverted-TK, and Introvert + wt show data for wild-type mice. Introvert + DAT-Cre shows survival of DAT-Cre mice after NAc injection of PRV-Introvert-GFP. Numbers in parentheses are the number of mice injected with each virus. D, PRV-Introvert injected into the NAc of wild-type $(1,3,5,7)$ or DAT-Cre $(2,4,6,8)$. Four days after injection, the brains were perfused, sectioned, and stained with anti-GFP. Scale bars: $250 \mu \mathrm{m}$.

such that after splicing, both GFP and PRV tk are coexpressed. We next confirmed that GFP was conditional on Cre expression (similar to tk), after PRV-Introvert-GFP infection.

GFP was not observed in PK15 cells infected with PRV-IntrovertGFP even though, as mentioned, $\mathrm{tk}^{-} \mathrm{PRV}$ strains can replicate in cultured PK15 cells. This showed that GFP was not expressed in cells without Cre-mediated recombination even when the virus could replicate (Fig. $2 B$, no Cre). In contrast, robust GFP expression was observed after infection of Cre-expressing PK15 cells with PRVIntrovert-GFP (Fig. 2B, +Cre). Similarly, PRV-Introvert-GFP in- jected into the NAc of wild-type mice failed to show any GFP expression despite that viral uptake was confirmed by expression of early PRV genes using immunohistochemistry (Fig. 2C, wild type). In contrast, injection of PRV-Introvert-GFP into the NAc of DATCre mice resulted in a high level of GFP expression in the VTA as well as neurons that project to the VTA (Fig. 2C, DAT-Cre). Thus, in mice infected with PRV-Introvert-GFP, both viral propagation and GFP expression are dependent on Cre expression.

We next characterized the upstream, polysynaptic inputs to dopaminergic VTA $\rightarrow$ NAc neurons by injecting PRV-Introvert 


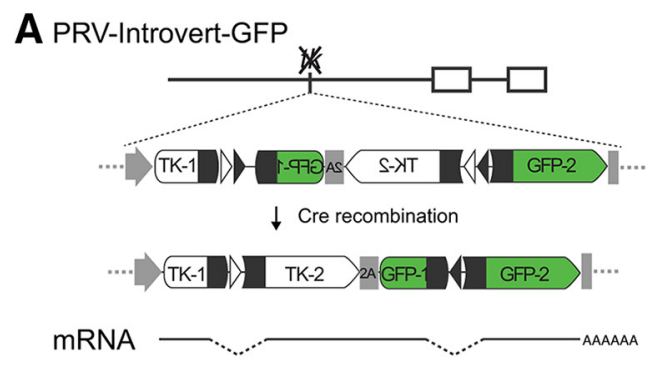

B Infected PK15 cells

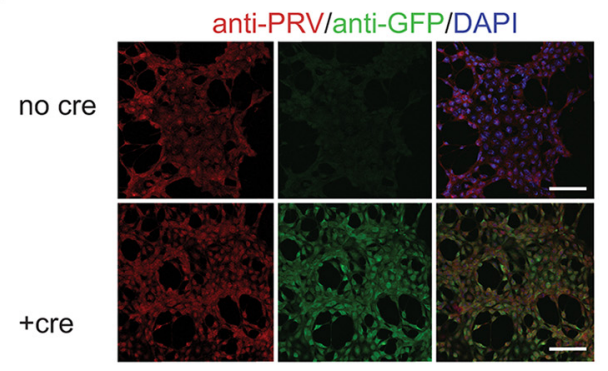

D Starter neurons

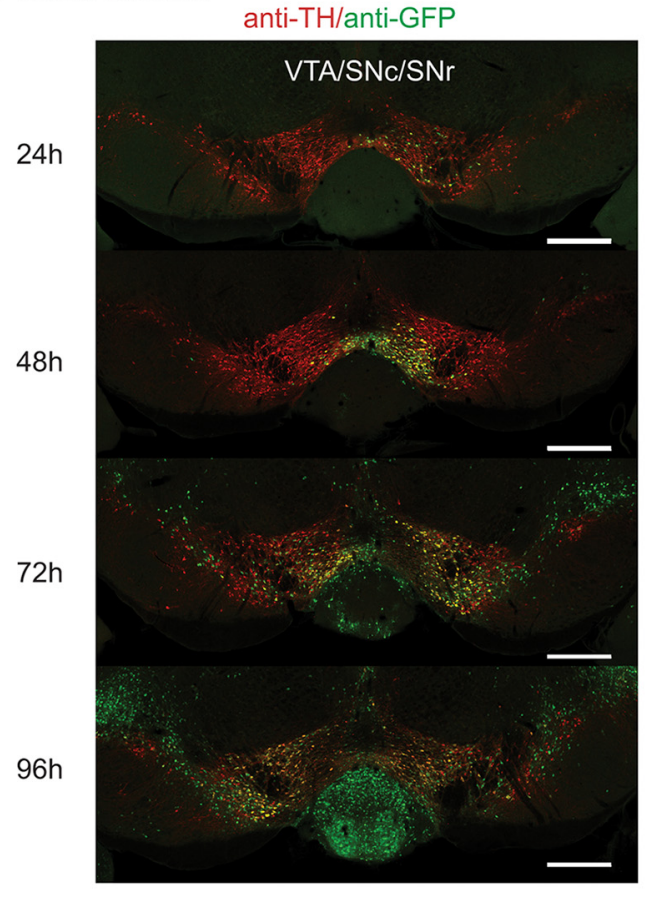

C
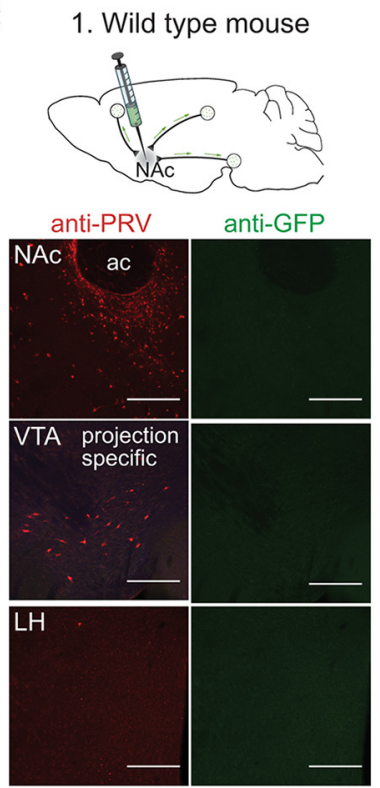

E Second+ order neurons

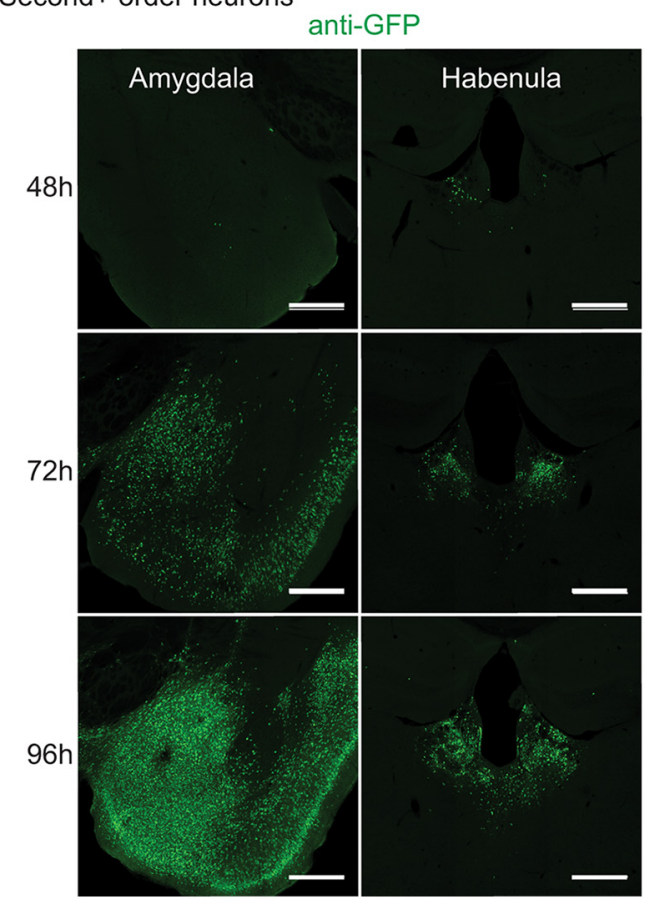

Figure 2. PRV-Introvert-GFP does not express GFP or spread in the CNS without Cre recombinase. A, Cre-dependent expression of PRV tk and GFP using a FLEX intron and 2A ribosomal skip sequence. Exposure to Cre inverts the $3^{\prime}$ exon of PRV tk (TK-2) and the $5^{\prime}$ exon of GFP (GFP-1) and excises one loxN (open triangles) and one lox2722 site (shaded triangles). The remaining lox sites are removed by splicing. $\boldsymbol{B}$, Cre recombinase is required for GFP expression during PRV-Introvert-GFP infection of PK15 cells. C, PRV-Introvert-GFP injection of wild-type and DAT-Cre mice. 1, Wild-type mouse showing limited expression of viral proteins and no GFP three days after NAc injection with PRV-Introvert-GFP. 2, Representative sections from DAT-Cre mouse four days post NAc injection. ac: anterior commissure. D, Time course of PRV spread in DAT-Cre 24, 48,72, and $96 \mathrm{~h}$ after bilateral injection in the NAc. Anti-TH staining marks dopamine neurons. $\boldsymbol{E}$, Structures infected 48,72 , and $96 \mathrm{~h}$ after infection that represent second or higher order connections to DAT-Cre starter cells in the VTA. Scale bars: $\boldsymbol{B}, 100 \mu \mathrm{m} ; \boldsymbol{C}, 250 \mu \mathrm{m} ; \boldsymbol{D}, \boldsymbol{E}, 500 \mu \mathrm{m}$.

GFP bilaterally into the NAc of DAT-Cre mice and performing immunohistochemistry for GFP after 1, 2, 3, and $4 \mathrm{~d}$. In these studies, because the infection spreads over multiple synapses each $24 \mathrm{~h}$, the precise input-output relationship of pairs of neurons cannot be confirmed. However, inferences about the higher order connectivity of a circuit can be drawn from analyses of retrograde spread over time (Card et al., 1999; Yoon et al., 2005). At $24 \mathrm{~h}$ after injection, GFP was seen only in TH-reactive VTA dopamine neurons (Fig. $2 D, 24 \mathrm{~h}$ ) indicating that Cre-mediated recombination occurs in these neurons within $24 \mathrm{~h}$ of PRV injection. This is consistent with in vitro data showing that Cremediated recombination occurs before replication of viral DNA at $\sim 6 \mathrm{~h}$ after infection (Kobiler et al., 2010). After $48 \mathrm{~h}$, spread of Cre-activated PRV was observed more extensively within the VTA, and GFP expression was also observed in non-TH neurons within the VTA and elsewhere. This indicates that the infection had spread to second (or higher) order neurons that do not express Cre, including the lateral habenula (LHb) and other sites 
A

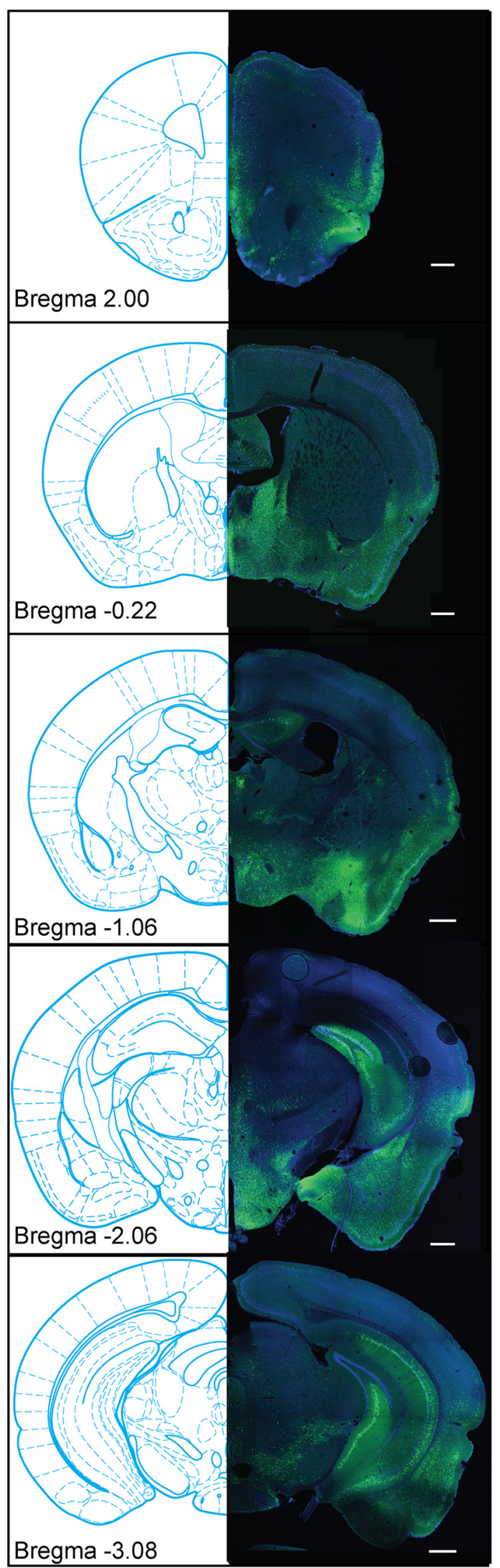

B

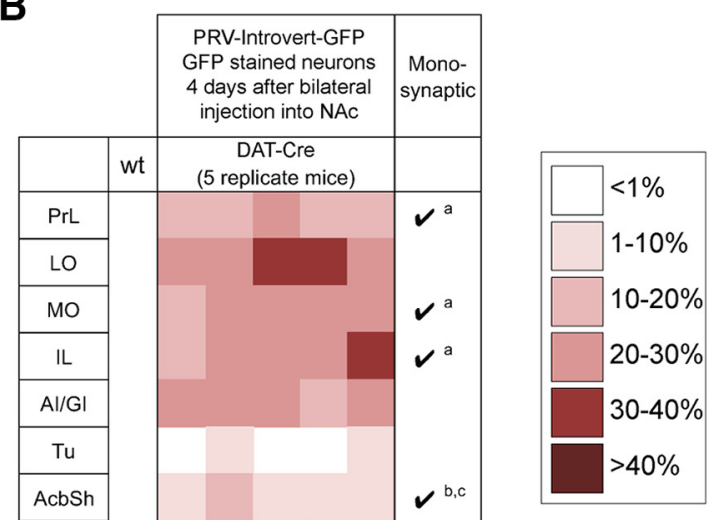

Figure 3. Main afferent targets of mesolimbic dopamine circuitry. $A$, Representative anti-GFP staining of structures that exhibit GFP reactivity after Cre-dependent retrograde tracing. Scale bars: $500 \mu \mathrm{m}$. B , Summary of tracing data $4 \mathrm{~d}$ after infection. Shown are one wild-type and five DAT-cre mice injected in the NAc PRV-Introvert-GFP. (Figure legend continues.) 
(Fig. 2E, 48 h). By 72 h, extensive GFP staining was observed in the LHb and Am (Fig. 2E, $72 \mathrm{~h}$ ). In mice that survived to $96 \mathrm{~h}$ after infection, GFP was expressed with a reproducible pattern in multiple other regions of the brain (Fig. $3 A$ ), including the piriform cortex, bed nucleus of the stria terminalis (BNST), medial preoptic nucleus, lateral preoptic nucleus, central amygdaloid nucleus, $\mathrm{LHb}, \mathrm{LH}$, arcuate hypothalamic nucleus (Arc), perirhinal cortex, VTA, and DRN. These data are summarized in Figure $3 B$ and are in agreement with numerous previous reports using other tracing methodologies for mapping presynaptic inputs to the VTA (Geisler and Zahm, 2005; Ikemoto, 2007; Lammel et al., 2012; Watabe-Uchida et al., 2012; Beier et al., 2015).

\section{Dual tracing shows little overlap between mesolimbic $\left(\mathrm{VTA}^{\mathrm{DAT}} \rightarrow \mathrm{NAc}\right)$ and nigrostriatal $\left(\mathrm{SNc}^{\mathrm{DAT}} \rightarrow\right.$ caudate putamen) dopamine pathways}

We next set out to develop a viral strain expressing mCherry that would, in combination with PRV Introvert GFP, allow simultaneous comparison of different circuits in the same animal. PRV-IntrovertmCherry is identical to PRV-Introvert-GFP except that it expresses HA-tagged mCherry instead of GFP (Fig. 4A, Introvert-mCherry). We next used these two viruses to simultaneously map the projections of dopaminergic neurons from the VTA to the NAc and from the $\mathrm{SN}$ to the caudate putamen $(\mathrm{CPu})$. Numerous studies using viral and non-viral retrograde tracers have previously shown that these are distinct neural circuits (Ikemoto, 2007; Watabe-Uchida et al., 2012) with very different functions. VTA $\rightarrow$ NAc playing a role in reward and reinforcement, while $\mathrm{SNc} \rightarrow \mathrm{CPu}$ dopamine neurons primarily regulate motor function (Dunnett, 2005).

PRV-Introvert-mCherry and PRV-Introvert-GFP are isogenic and, as shown in previous reports (Jansen et al., 1995; Banfield et al., 2003; Cano et al., 2004; Card et al., 2011), replicate at the same rate (Fig. 4B). We injected PRV-Introvert-GFP and PRV-IntrovertmCherry into the NAc and $\mathrm{CPu}$, respectively, and analyzed sections from these mice after $4 \mathrm{~d}$ (Fig. $4 C$ ). We observed markedly different patterns of GFP and mCherry expression, thus identifying distinct inputs to the mesolimbic (labeled with GFP) and nigrostriatal pathways (labeled with HA-mCherry). Moreover, even when the same

\section{$\leftarrow$}

(Figure legend continued.) No anti-GFP reactivity was detected in a wild-type mouse injected as a control. Monosynaptic connectivity of structures was established in previous studies as indicated: a, Monosynaptic connection from anterior cortex to VTA dopamine neurons projecting to the lateral NAc (Beier et al., 2015); $b$, number of input neurons $\geq 200 / 10,000$ total inputs to VTA dopamine neurons (Watabe-Uchida et al., 2012); c, monosynaptic connections to both medial and lateral NAc-projecting VTA dopamine neurons $\geq 5 \%$ (Beier et al., 2015); d, monosynaptic connections to lateral NAc-projecting VTA dopamine neurons $\geq 5 \%$ (Beier et al., 2015); e, monosynaptic connections from dorsal striatum to lateral NAc-projecting VTA dopamine neurons (Beier et al., 2015); f, monosynaptic connections from the preoptic area to both medial and lateral NAc-projecting VTA dopamine neurons (Beier et al., 2015); g, monosynaptic connections to medial NAc-projecting VTA dopamine neurons $\geq 5 \%$ (Beier et al., 2015). PrL, Prelimbic cortex; L0, lateral orbital cortex; M0, medial orbital cortex; L, infralimbic cortex; $\mathrm{Al} / \mathrm{Gl}$, insular cortex (granular/agranular); Tu, olfactory tubercle; AcbSh, nucleus accumbens shell; AcbC, nucleus accumbens core; M1/M2, motor cortex (primary/secondary); S1/S2, somatosensory cortex (primary/secondary); Pir, piriform cortex; LSI, lateral intermediate septal nucleus; VP, ventral pallidum; HDB, nucleus of the horizontal limb of the diagonal band; IPAC, interstitial nucleus of the posterior limb of the anterior commissure; GP, globus pallidus; MPO, medial preoptic nucleus; LPO, lateral preoptic nucleus; EA, sublenticular extended amygdala; CeA central amygdaloid nucleus; $\mathrm{MHb}$, medial habenular nucleus; $\mathrm{PaV}$, paraventricular hypothalamic nucleus; TuLH, tuberal region of the hypothalamus; $\mathrm{VMH}$, ventromedial hypothalamic nucleus; Zl, zona incerta; PRh, perirhinal cortex; Au, auditory cortex; V, visual cortex; Ent, entorhinal cortex; PeF Perifornical nucleus; PSTh, parasubthalamic nucleus; STh, subthalamic nucleus; SNC, substantia nigra compact part; SNR, substantia nigra reticular part; MM, supramammilary nucleus; PAG, periaqueductal gray; RRF, retrorubral field. brain region showed infection with both viruses, such as the LH, only red or green neurons were seen in the section, with very limited coexpression of both markers (yellow). The results were similar when the injection sites of PRV-Introvert-GFP and PRV-IntrovertmCherry were reversed (PRV-Introvert-GFP in CPu, PRV-Introvert-mCherry in NAc) or when the viruses were injected individually into different animals (data not shown). These dual-tracing studies recapitulate previous mapping of inputs to the nigrostriatal and mesolimbic dopamine pathways and confirm that these pathways are distinct from each other (Geisler and Zahm, 2005; Watabe-Uchida et al., 2012). In addition, these studies show that PRV-Introvert retrograde tracing travels within synaptically connected neural circuits without viral spread between adjacent neurons that are not synaptically connected (for review, see Pomeranz et al., 2005).

In aggregate, these experiments confirm that PRV-IntrovertGFP can be used for retrograde tracing of polysynaptic inputs to Cre-expressing neurons without spread between anatomically comingled neurons. We next set out to use this approach to determine the molecular identity of the synaptically connected neurons we had visualized by retrograde tracing.

\section{Transcriptional profiling of neural circuits with PRV- Introvert-GFP}

We previously published Retro-TRAP, a method to use expression of soluble GFP to precipitate GFP-binding ribosomes (NBL10) from infected neurons (Ekstrand et al., 2014). As shown in Figures 2-4, Cre activation of PRV-Introvert-GFP leads to expression of GFP in neurons projecting directly or indirectly to dopaminergic VTA ${ }^{\text {DAT-Cre }} \rightarrow$ NAc neurons. To molecularly profile this circuit, we mated DAT-Cre to SYN-NBL10 mice and injected PRV-Introvert-GFP into the NAc. GFP expressed from PRV-Introvert-GFP binds to the NBL10-tagged polysomes and is then precipitated using anti-GFP monoclonal antibodies (Fig. $5 A$ ). IP RNA was purified along with total RNA collected before immunoprecipitation (input RNA), and the enrichment of transcripts in our IP fraction was analyzed as described in Materials and Methods.

As expected, Gfp, which is expressed only in infected neurons, was enriched ninefold in IP RNA compared with Input RNA (Fig. 5B). In addition, Slc6a3 (Dat), a marker for dopamine neurons in the VTA, was also enriched in the IP fraction, while Anxa1, a marker for midbrain neurons found mostly in the SN but not the VTA (Lein et al., 2007), was depleted. Because the input sample contained DAT-Cre neurons from both VTA and SNc, the enrichment of Dat and the depletion of Anxal confirms that the immunoprecipitation successfully isolated RNA from neurons in the VTA $\rightarrow$ NAc circuit and not from nigrostriatal dopaminergic neurons. As reported previously, the synapsin promoter directs expression of NBL10 specifically to neurons (Ekstrand et al., 2014), and the expression of Gfap, a marker of nonneuronal glial cells, was also depleted in the IP RNA (Fig. 5B, Gfap).

Having validated our ability to enrich for RNA from infected neurons, we next used high-throughput RNA sequencing to profile the RNA samples. RNA quality was analyzed on an Agilent Genomics 2100 Bioanalyzer (Fig. 5C), and the RNA was sequenced with an Illumina HiSeq 2000 system. Sequencing results were processed using TopHat and Cufflinks as described in Materials and Methods. The relative expression of individual genes was plotted as fragments per kilobase of transcript per million mapped reads of IP RNA versus input RNA (Fig. 5D).

As expected, PRV infection affects expression of a subset of cellular messages in CNS tissue (Ray and Enquist, 2004; Paulus et al., 
A PRV-Introvert-GFP

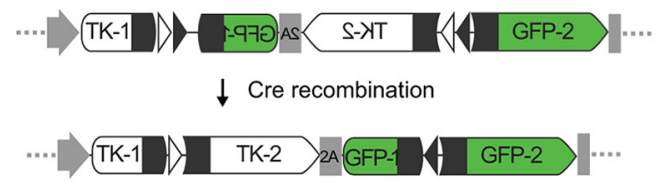

PRV-Introvert-mCherry

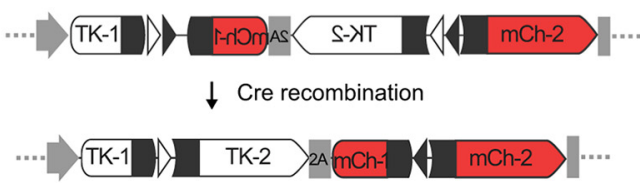

\section{B Dual infection}

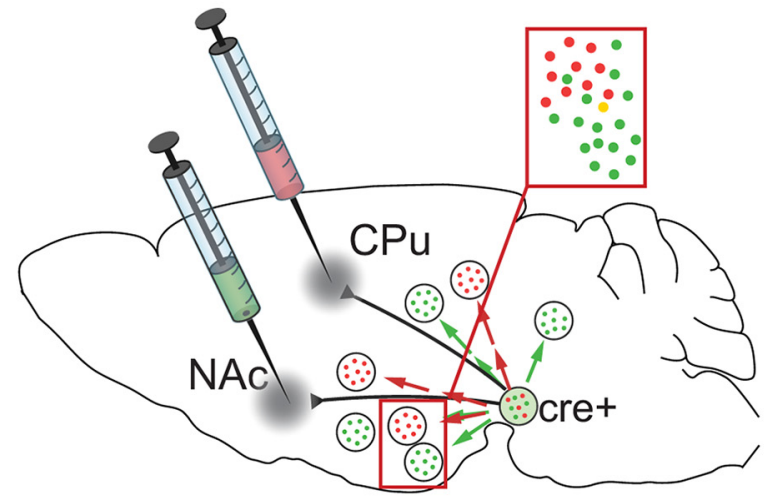

C
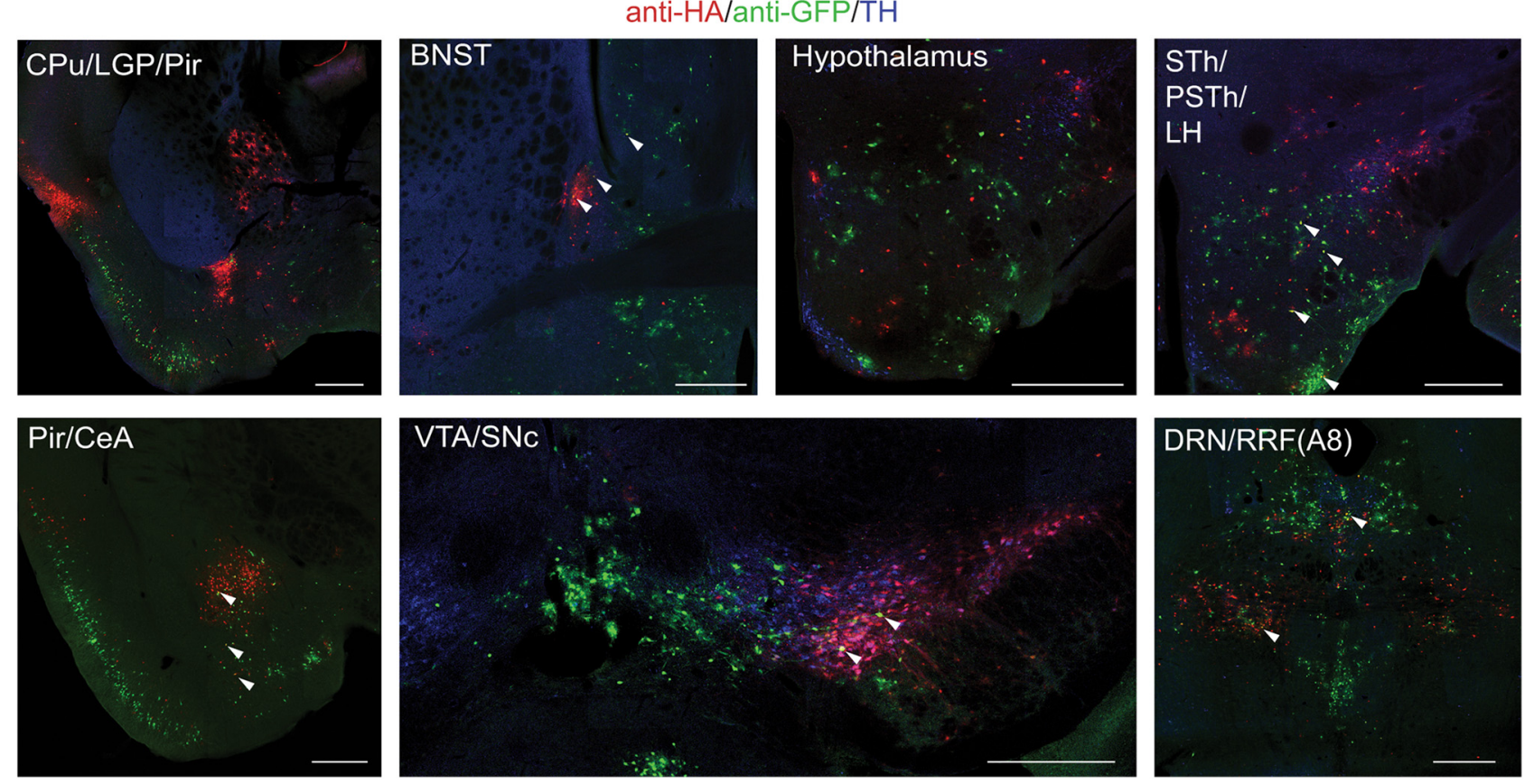

Figure 4. Dual tracing of inputs to CPu- and NAc-projecting dopamine neurons shows specificity of retrograde labeling and minimal cross talk between circuitry. $\boldsymbol{A}$, PRV-Introvert$\mathrm{mCherry}$ is identical to PRV-Introvert-GFP except that GFP has been replaced with HA-mCherry. $\boldsymbol{B}$, Dual injection in the NAc and CPu with isogenic strains of PRV-Introvert results in only a few neurons infected with both viruses (yellow). C, PRV-Introvert-GFP and PRV-Introvert-mCherry were injected into the right NAc and CPu, respectively, of DAT-Cre mice. Four days after injection, brains were assayed for anti-HA (red) and anti-GFP (green) staining. Arrowheads denote neurons expressing both red and green label. Scale bars: $500 \mu \mathrm{m}$. Abbreviations are defined in the Figure 3 legend.

2006; Flori et al., 2008; Szpara et al., 2010; Harkness et al., 2014; Oláh et al., 2015; Hu et al., 2016). We identified 722 genes that were significantly upregulated (more than twofold upregulated, $q$ value $<0.05$ ) and 161 genes that were significantly downregulated (more than twofold downregulated, $q$ value $<0.05$ ) in infected CNS tissue. A list of differentially expressed genes representing the most highly upregulated in PRV infected samples are shown in Table 1. Twentythree of the top 100 upregulated genes were identified in a previous study of PRV-Bartha-infected rat CNS (Table 1; Paulus et al., 2006). Notably, 87 of the 100 genes shown in Table 1 were also upregulated in brain tissue isolated from mice infected with attenuated rabies (strain HEP-Flury), and 91 were upregulated in brain tissue isolated after infection with virulent rabies (strain CVS-11; Zhang et al., 2016). Using tools provided by the Gene Ontology Consortium (Ashburner et al., 2000; Gene Ontology Consortium, 2015; http:// geneontology.org/page/go-enrichment-analysis) we identified biological processes that were significantly overrepresented among the
722 upregulated genes. Eighty-six of the top 100 upregulated genes could be further subdivided into four ontological families: immune response, response to viral infection, apoptosis, and ubiquitination (Table 1). No significant gene ontology (GO) associations were detected for the 161 downregulated genes.

The findings presented in Table 1 indicate a substantial stress response in PRV infected neurons that may affect our ability to detect neuronal marker transcripts using PRV-Circuit-TRAP. To account for possible effects of PRV infection on gene expression, the ratio of average gene expression (in fragments per kilobase of transcript per million mapped reads) of infected to control RNA was used to calculate a weighted enrichment value for each gene (see Materials and Methods). Based on the weighted values, the 60 genes most highly enriched in our IP RNA sample are listed in Table 2. A subset of the enriched genes that are known to be expressed in hypothalamus and midbrain markers are highlighted in Figure 5D. 


\section{A PRV Circuit-TRAP}

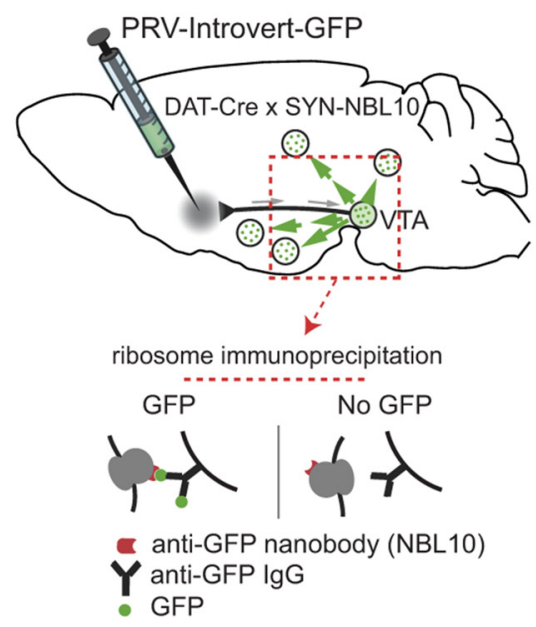

B

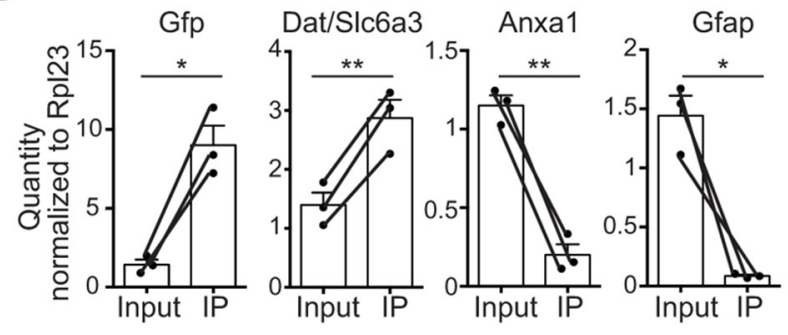

C

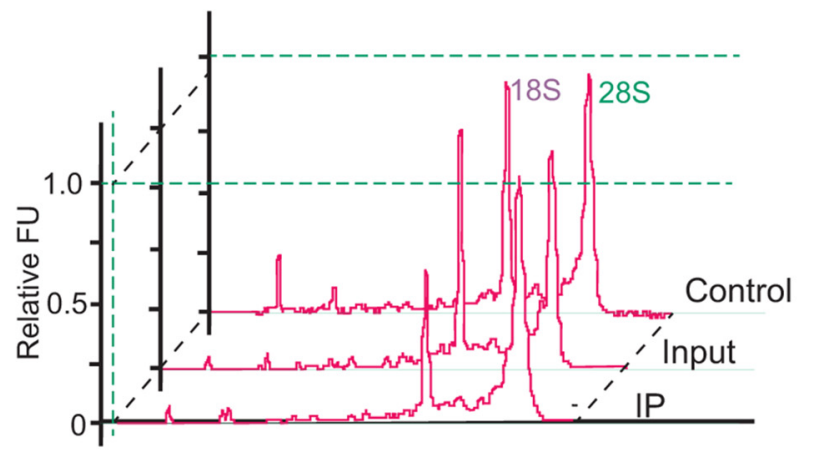

D

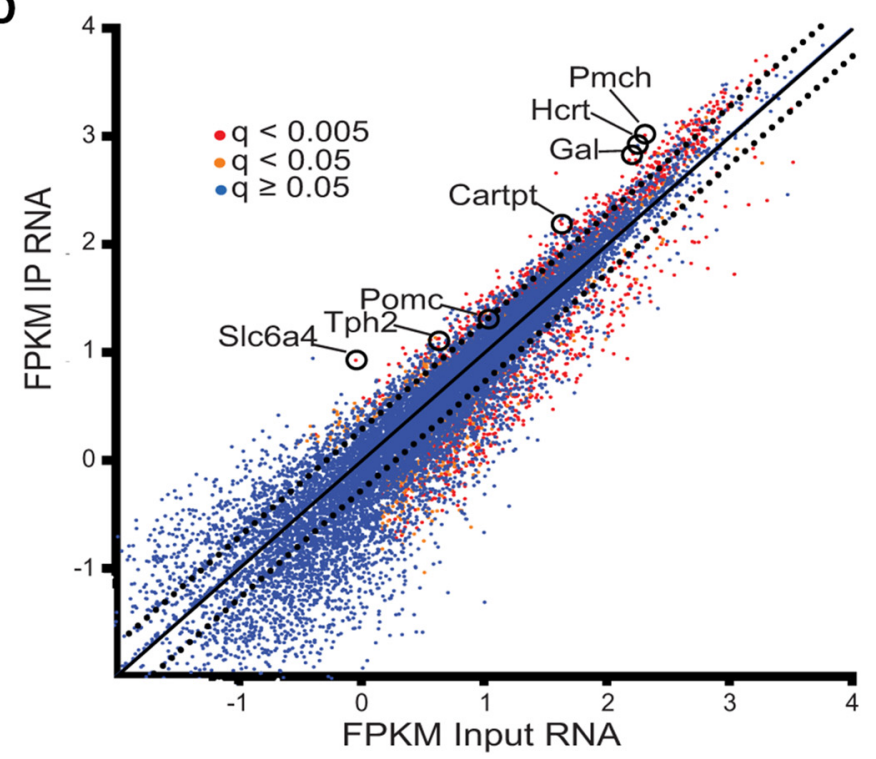

Figure 5. PRV-Circuit-TRAP of hypothalamic and midbrain neurons projecting to the mesolimbic dopamine circuit. $A$, Strategy for PRV-Circuit-TRAP. PRV-Introvert-GFP was injected bilaterally into the NAC of DAT-Cre $\times$ SYN-NBL10 mice. Translating ribosomes tagged with GFP binding nanobody (NBL10) were immunoprecipitated from a section of midbrain 3 days after injection of PRV-Introvert-GFP. $\boldsymbol{B}$, Results of qPCR of input and IP samples from PRV-Circuit-TRAP for Gfp $(p<0.05)$, Dat/Slc6a3 $(p<0.01)$, Anxa1 $(p<0.01)$, and Gfap $(p<0.05)$. Fold enrichment for each gene from the IP or input sample is normalized to the housekeeping gene Rp/23. C, Electropherogram of representative control, input, and IP RNA samples measured on an Agilent 2100 Bioanalyzer before sequencing on an Illumina HiSeq 2000. D. Differential enrichment of immunoprecipitated transcripts. Dotted lines indicate twofold enrichment or depletion in IP RNA compared with input RNA. Colors of dots indicate the significance of enrichment: red, $q<0.005$; orange, $q<0.05$; blue, $q \geq 0.05 .{ }^{*} p<0.05 ; * * p<0.01$.

\section{Dorsal raphe projections to the dopaminergic mesolimbic circuit}

Several RNAs for genes known to be expressed in the DRN and the LH were identified. While the DRN and LH have been shown to send inputs to dopaminergic neurons in the VTA, the specific molecular markers expressed by these neurons have not been systematically characterized. The serotonin transporter Slc6a4/ SERT was enriched $>12$-fold after IP, making it the most highly enriched transcript (Table 2). Tryptophan hydroxylase (Tph2), the rate-limiting enzyme in the synthesis of serotonin, was also highly enriched, suggesting that serotonergic neurons in the DRN project to the VTA ${ }^{\mathrm{DAT}} \rightarrow \mathrm{NAc}$ circuit. To confirm that DRN transcripts identified using PRV-Circuit-TRAP mark a $\mathrm{DRN} \rightarrow \mathrm{VTA}^{\mathrm{DAT}} \rightarrow \mathrm{NAc}$ pathway, we injected PRV-IntrovertGFP into the NAc of DAT-Cre mice and quantified the colocalization of virally expressed GFP with a subset of marker genes that were enriched after polysome precipitation. The DRN can be subdivided into four sections defined by increased Tph2-reactivity: dorsomedial (DRD), ventromedial (DRV), and two dorsolateral wings (DRL; Fig. 6A; Franklin and Paxinos, 2008; Vasudeva et al., 2011). We quantified the density of Tph2 neurons projecting to the VTA by anti-Tph2 staining and found that colocalization of GFP and $\mathrm{Tph} 2$ was limited largely to the ventral aspect of the dorsal raphe nucleus with only limited colocalization in the lateral and dorsal regions (Fig. $6 A, B$ ). On average, $52.2 \%$ of Tph2-stained DRV neurons and only $15.4 \%$ of Tph2 expressing neurons in the DRD and DRL projected from the dorsal raphe to the mesolimbic dopamine circuit (Fig. 6C). A significant number of cells were GFP positive but Tph2 negative, indicating that nonserotonergic neurons of the DRN also project to the dopaminergic mesolimbic circuit, particularly from the DRL and DRD (Fig. 6D).

\section{LH projections to the mesolimbic dopamine circuit}

The LH is composed of a heterogeneous population of neurons that project broadly throughout the CNS and regulate numerous behaviors including food intake and energy expenditure. To confirm that transcripts identified by PRV-Circuit-TRAP were enriched in the $\mathrm{LH} \rightarrow \mathrm{VTA}^{\mathrm{DAT}} \rightarrow \mathrm{NAc}$ pathway, we injected PRVIntrovert-GFP into the NAc of DAT-Cre mice and quantified the colocalization of GFP with markers expressed in LH neurons that were enriched after polysome precipitation.

Melanin-concentrating hormone (Pmch), orexin/Hcrt, cocaineand amphetamine-related prepropeptide transcript (Cartpt), neurotensin (Nts), and galanin (Gal) were among the most highly expressed transcripts in the polysome fraction, and we confirmed their enrichment with qPCR (Fig. 7A). We also found that after 
Table 1. List of 100 genes most highly enriched in PRV-infected mouse CNS

\begin{tabular}{|c|c|c|c|c|c|c|c|c|c|c|c|c|}
\hline & Description & Gene ID & $\begin{array}{l}\text { Fold increase } \\
\text { (infected// } \\
\text { control; log2) }\end{array}$ & qvalue & $\begin{array}{l}\text { Immune } \\
\text { response } \\
(71)^{a}\end{array}$ & $\begin{array}{l}\text { Response to } \\
\text { interferon } \\
(32)^{b}\end{array}$ & $\begin{array}{l}\text { Defense response } \\
\text { to virus/viral } \\
\text { process }(40)^{c}\end{array}$ & $\begin{array}{l}\text { Apoptosis } \\
(30)^{d}\end{array}$ & $\begin{array}{l}\text { Protein } \\
\text { ubiquitination } \\
(10)^{e}\end{array}$ & $\begin{array}{l}\text { Upregulated } \\
\text { in PRV-infected } \\
\text { rat CNS }(23)^{f}\end{array}$ & $\begin{array}{l}\text { Upregulated } \\
\text { in virulent } \\
\text { rabies }(91)^{g}\end{array}$ & $\begin{array}{l}\text { Upregulated } \\
\text { in attenuated } \\
\text { rabies }(87)^{h} \\
\end{array}$ \\
\hline 1 & Chemokine (C-C motif) ligand 2 & $\mathrm{C} 12$ & 8.15 & 0.00073 & $\checkmark$ & $\checkmark$ & $\checkmark$ & $\checkmark$ & & $\checkmark$ & $\checkmark$ & $\checkmark$ \\
\hline 2 & Interferon regulatory factor 7 & Irf7 & 7.98 & 0.00073 & $s$ & $\checkmark$ & $\checkmark$ & $\checkmark$ & & $\checkmark$ & $\checkmark$ & $\checkmark$ \\
\hline 3 & Ubiquitin specific peptidase 18 & Usp18 & 7.84 & 0.00073 & & & & & $\checkmark$ & & $\checkmark$ & $\checkmark$ \\
\hline 4 & Interferon-induced protein with tetratricopeptide repeats 1 & Ifit1 & 7.66 & 0.00073 & $\checkmark$ & $\checkmark$ & $\checkmark$ & & & & $\checkmark$ & $\checkmark$ \\
\hline 5 & Chemokine (C-C motif) ligand 12 & Cd12 & 7.50 & 0.00073 & $\checkmark$ & $\checkmark$ & & & & & $\checkmark$ & $\checkmark$ \\
\hline 6 & ISG15 ubiquitin-like modifier & $\operatorname{lsg} 15$ & 7.17 & 0.00073 & $\checkmark$ & $\checkmark$ & $\checkmark$ & & & & $\checkmark$ & $\checkmark$ \\
\hline 7 & Chemokine (C-Cmotif) ligand 7 & $\mathrm{Cd} 7 \mathrm{C}$ & 6.93 & 0.00073 & $s$ & $\checkmark$ & & & & & & \\
\hline 8 & 2'-5' oligoadenylate synthetase-like 2 & Oas 12 & 6.82 & 0.00073 & $\checkmark$ & & $\checkmark$ & & & & $\checkmark$ & $\checkmark$ \\
\hline 9 & Interferon gamma inducible protein 47 & Ifi47 & 6.82 & 0.00073 & $\checkmark$ & $\checkmark$ & & & & & $\checkmark$ & $\checkmark$ \\
\hline 10 & Interferon-induced protein with tetratricopeptide repeats 3 & Ifit3 & 6.60 & 0.00073 & $\checkmark$ & $\checkmark$ & $\checkmark$ & $\checkmark$ & & & $\checkmark$ & $\checkmark$ \\
\hline 11 & Interferon, alpha-inducible protein 27 like $2 \mathrm{~A}$ & Ifi27/2a & 6.55 & 0.00073 & $\checkmark$ & $\checkmark$ & $\checkmark$ & & & & $\checkmark$ & $\checkmark$ \\
\hline 12 & $2^{\prime}-5$ ' oligoadenylate synthetase $1 \mathrm{~A}$ & Oas1a & 6.47 & 0.00073 & $\checkmark$ & & $\checkmark$ & & & $\checkmark$ & & \\
\hline 13 & Guanylate binding protein 2 & Gbp2 & 6.41 & 0.00073 & $\checkmark$ & $\checkmark$ & $\checkmark$ & & & $\checkmark$ & & \\
\hline 14 & Chemokine (C-Cmotif) ligand 5 & $C(15$ & 6.34 & 0.00073 & $\checkmark$ & $\checkmark$ & $\checkmark$ & $\checkmark$ & & & $\checkmark$ & $\checkmark$ \\
\hline 15 & Bone marrow stromal cell antigen 2 & Bst2 & 6.34 & 0.00073 & $\checkmark$ & $\checkmark$ & $\checkmark$ & & & & $\checkmark$ & $\checkmark$ \\
\hline 16 & RIKEN CDNA 1830012016 gene & 1830012016Rik & 6.26 & 0.00073 & $\checkmark$ & & $\checkmark$ & & & & $\checkmark$ & $\checkmark$ \\
\hline 17 & Receptor transporter protein 4 & Rtp4 & 6.11 & 0.00073 & & & & & & & $\checkmark$ & $\checkmark$ \\
\hline 18 & $\begin{array}{l}\text { Leukocyte immunoglobulin-like receptor, subfamily B, } \\
\text { member } 4\end{array}$ & Lilrb4 & 6.00 & 0.00073 & $\checkmark$ & & & & & & & \\
\hline 19 & Guanylate binding protein 3 & Gbp3 & 5.99 & 0.00073 & $\checkmark$ & $\checkmark$ & $\checkmark$ & & & & $\checkmark$ & $\checkmark$ \\
\hline 20 & Membrane-spanning 4-domains, subfamily A, member 6D & Ms4a6d & 5.98 & 0.00073 & & & & & & & $\checkmark$ & $\checkmark$ \\
\hline 21 & T-cell specific GTPase 2 & Tgtp2 & 5.92 & 0.00073 & $\checkmark$ & & & & & & $\checkmark$ & $\checkmark$ \\
\hline 22 & Myxovirus (influenza virus) resistance 2 & Mx2 & 5.80 & 0.00073 & $\checkmark$ & $\checkmark$ & $\checkmark$ & & & $\checkmark$ & $\checkmark$ & $\checkmark$ \\
\hline 23 & Guanylate binding protein 7 & Gbp7 & 5.63 & 0.00073 & $\checkmark$ & $\checkmark$ & & & & & & \\
\hline 24 & Sterile alpha motif domain containing 9-like & Samdgl & 5.35 & 0.00073 & $\checkmark$ & & & & & & $\checkmark$ & $\checkmark$ \\
\hline 25 & Interferon-induced protein with tetratricopeptide repeats 2 & Ifit2 & 5.32 & 0.00073 & $\checkmark$ & $\checkmark$ & $\checkmark$ & $\checkmark$ & & & $\checkmark$ & $\checkmark$ \\
\hline 26 & Membrane-spanning 4-domains, subfamily A, member $6 \mathrm{C}$ & Ms4abc & 5.26 & 0.00073 & & & & & & & $\checkmark$ & $\checkmark$ \\
\hline 27 & DEAD (Asp-Glu-Ala-Asp) box polypeptide 58 & $D d \times 58$ & 5.13 & 0.00073 & $\checkmark$ & & $\checkmark$ & & & & $\checkmark$ & $\checkmark$ \\
\hline 28 & Schlafen 2 & SIfn2 & 5.12 & 0.00073 & & & & & & & $\checkmark$ & $\checkmark$ \\
\hline 29 & Immunity-related GTPase family M member 1 & $\operatorname{Irgm} 1$ & 5.09 & 0.00073 & $\checkmark$ & & & & & & $\checkmark$ & $\checkmark$ \\
\hline 30 & Interferon gamma induced GTPase & lgtp & 5.03 & 0.00073 & $\checkmark$ & $\checkmark$ & & & & & $\checkmark$ & $\checkmark$ \\
\hline 31 & Hect domain and RLD 6 & Herc6 & 5.01 & 0.00073 & $\checkmark$ & & & & $\checkmark$ & & & \\
\hline 32 & Tripartite motif-containing 30D & Trim30d & 4.99 & 0.00073 & $\checkmark$ & & & & & & & \\
\hline 33 & Membrane-spanning 4-domains, subfamily A, member 6B & Ms4a6b & 4.95 & 0.00073 & & & & & & & $\checkmark$ & $\checkmark$ \\
\hline 34 & Proteasome subunit, beta type 8 & Psmb8 & 4.91 & 0.00073 & $\checkmark$ & $\checkmark$ & $\checkmark$ & & $\checkmark$ & $\checkmark$ & $\checkmark$ & $\checkmark$ \\
\hline 35 & Lipocalin 2 & Len2 & 4.91 & 0.00073 & $\checkmark$ & & $\checkmark$ & & & & $\checkmark$ & $\checkmark$ \\
\hline 36 & Interleukin 2 receptor, gamma chain & $\| 2 r g$ & 4.83 & 0.00073 & $\checkmark$ & & $\checkmark$ & & & & $\checkmark$ & $\checkmark$ \\
\hline 37 & Activating transcription factor 3 & Atf3 & 4.73 & 0.00073 & & & & $\checkmark$ & & $\checkmark$ & $\checkmark$ & $\checkmark$ \\
\hline 38 & Interferon induced transmembrane protein 3 & Ifitm3 & 4.60 & 0.00073 & $\checkmark$ & $\checkmark$ & $\checkmark$ & & & & $\checkmark$ & $\checkmark$ \\
\hline 39 & Interferon regulatory factor 9 & Irfg & 4.60 & 0.00073 & $\checkmark$ & $\checkmark$ & $\checkmark$ & & & & $\checkmark$ & $\checkmark$ \\
\hline 40 & Nuclear antigen Sp100 & Sp100 & 4.60 & 0.00073 & $\checkmark$ & $\checkmark$ & $\checkmark$ & $\checkmark$ & & & $\checkmark$ & $\checkmark$ \\
\hline 41 & CD274 antigen & $C d 274$ & 4.59 & 0.00073 & $\checkmark$ & & & $\checkmark$ & & & $\checkmark$ & $\checkmark$ \\
\hline 42 & $\begin{array}{l}\text { Transporter 1, ATP-binding cassette, sub-family B } \\
\text { (MDR/TAP) }\end{array}$ & Tap1 & 4.58 & 0.00073 & $\checkmark$ & & $\checkmark$ & & & $\checkmark$ & $\checkmark$ & $\checkmark$ \\
\hline 43 & Poly (ADP-ribose) polymerase family, member 10 & Parp10 & 4.55 & 0.00073 & & & $\checkmark$ & $\checkmark$ & $\checkmark$ & & $\checkmark$ & $\checkmark$ \\
\hline 44 & Interferon-stimulated protein & $\operatorname{lsg} 20$ & 4.45 & 0.00073 & $\checkmark$ & $\checkmark$ & $\checkmark$ & & & & $\checkmark$ & $\checkmark$ \\
\hline 45 & Proteasome subunit, beta type 9 & Psmb9 & 4.42 & 0.00073 & $\checkmark$ & & $\checkmark$ & & $\checkmark$ & $\checkmark$ & $\checkmark$ & $\checkmark$ \\
\hline 46 & Eukaryotic translation initiation factor 2-alpha kinase 2 & Eif2ak2 & 4.41 & 0.00073 & $\checkmark$ & $\checkmark$ & $\checkmark$ & $\checkmark$ & & $\checkmark$ & $\checkmark$ & $\checkmark$ \\
\hline 47 & Signal transducer and activator of transcription 1 & Stat1 & 4.40 & 0.00073 & $\checkmark$ & $\checkmark$ & $\checkmark$ & $\checkmark$ & & $\checkmark$ & $\checkmark$ & $\checkmark$ \\
\hline 48 & Poly (ADP-ribose) polymerase family, member 9 & Parp9 & 4.40 & 0.00073 & & & $\checkmark$ & $\checkmark$ & $\checkmark$ & & $\checkmark$ & $\checkmark$ \\
\hline 49 & Immunity-related GTPase family M member 2 & $\operatorname{Irgm} 2$ & 4.37 & 0.00073 & $\checkmark$ & & & & & & $\checkmark$ & $\checkmark$ \\
\hline 50 & Interferon-induced protein 35 & Ifi35 & 4.36 & 0.00073 & $\checkmark$ & $\checkmark$ & & & & & $\checkmark$ & $\checkmark$ \\
\hline 51 & Lectin, galactose binding, soluble 9 & Lgals9 & 4.35 & 0.00073 & $\checkmark$ & $\checkmark$ & $\checkmark$ & $\checkmark$ & & $\checkmark$ & $\checkmark$ & $\checkmark$ \\
\hline 52 & Expressed sequence AW112010 & AW112010 & 4.33 & 0.00073 & & & & & & & $\checkmark$ & $\checkmark$ \\
\hline 53 & Interleukin 18 binding protein & $\| 18 b p$ & 4.32 & 0.00073 & $\checkmark$ & & & & & & $\checkmark$ & $\checkmark$ \\
\hline 54 & CD72 antigen & $C d 72$ & 4.30 & 0.00073 & $\checkmark$ & & & & & & $\checkmark$ & $\checkmark$ \\
\hline 55 & G protein-coupled receptor 84 & Gpr84 & 4.28 & 0.00073 & $\checkmark$ & & & & & & $\checkmark$ & $\checkmark$ \\
\hline 56 & Heat shock protein 1 & Hspb1 & 4.19 & 0.00073 & & & $s$ & $\checkmark$ & & $\checkmark$ & $\checkmark$ & $\checkmark$ \\
\hline 57 & Fc receptor, IgG, high affinity I & Fcgr1 & 4.16 & 0.00073 & $\checkmark$ & $\checkmark$ & & & & & $\checkmark$ & $\checkmark$ \\
\hline 58 & Cyclin-dependent kinase inhibitor 1A (P21) & Cdkn1a & 4.15 & 0.00073 & & & & $\checkmark$ & & & $\checkmark$ & $\checkmark$ \\
\hline 59 & Deltex 3-like (Drosophila) & $D+x 31$ & 4.15 & 0.00073 & $\checkmark$ & & $\checkmark$ & & $\checkmark$ & & $\checkmark$ & $\checkmark$ \\
\hline 60 & Plasminogen activator, urokinase receptor & Plaur & 4.14 & 0.00073 & & & & $\checkmark$ & & & $\checkmark$ & $\checkmark$ \\
\hline 61 & Lectin, galactoside-binding, soluble, 3 binding protein & Lgals3bp & 4.12 & 0.00073 & $\checkmark$ & & & & & $\checkmark$ & $\checkmark$ & $\checkmark$ \\
\hline 62 & Histocompatibility 2, K1, K region & $H 2-K 1$ & 4.11 & 0.00073 & $\checkmark$ & & & & & & $\checkmark$ & $\checkmark$ \\
\hline 63 & Histocompatibility 2, T region locus 23 & H2-T23 & 4.11 & 0.00073 & $\checkmark$ & & & & & & $\checkmark$ & $\checkmark$ \\
\hline 64 & Tripartite motif-containing 34A & Trim $34 a$ & 3.97 & 0.00073 & $\checkmark$ & & $\checkmark$ & & & & $\checkmark$ & $\checkmark$ \\
\hline 65 & CD52 antigen & Cd52 & 3.96 & 0.00073 & $\checkmark$ & & & & & & $\checkmark$ & $\checkmark$ \\
\hline 66 & Ubiquitin-like modifier activating enzyme 7 & Uba7 & 3.95 & 0.00073 & & & & & $\checkmark$ & & $\checkmark$ & $\checkmark$ \\
\hline 67 & Torsin family 3 , member A & Tor3a & 3.94 & 0.00073 & $\checkmark$ & & & & & & $\checkmark$ & $\checkmark$ \\
\hline 68 & Poly (ADP-ribose) polymerase family, member 12 & Parp12 & 3.89 & 0.00073 & & & $\checkmark$ & $\checkmark$ & $\checkmark$ & & $\checkmark$ & $\begin{array}{l}\checkmark \\
\text { Table Continues) }\end{array}$ \\
\hline
\end{tabular}


Table 1. (continued)

\begin{tabular}{|c|c|c|c|c|c|c|c|c|c|c|c|c|}
\hline & Description & Gene ID & $\begin{array}{l}\text { Fold increase } \\
\text { (infected/ } \\
\text { control; } \log 2 \text { ) }\end{array}$ & $q$ value & $\begin{array}{l}\text { Immune } \\
\text { response } \\
(71)^{a}\end{array}$ & $\begin{array}{l}\text { Response to } \\
\text { interferon } \\
(32)^{b}\end{array}$ & $\begin{array}{l}\text { Defense response } \\
\text { to virus/viral } \\
\text { process }(40)^{c}\end{array}$ & $\begin{array}{l}\text { Apoptosis } \\
(30)^{d}\end{array}$ & $\begin{array}{l}\text { Protein } \\
\text { ubiquitination } \\
(10)^{e}\end{array}$ & $\begin{array}{l}\text { Upregulated } \\
\text { in PRV-infected } \\
\text { rat CNS }(23)^{f}\end{array}$ & $\begin{array}{l}\text { Upregulated } \\
\text { in virulent } \\
\text { rabies }(91)^{g}\end{array}$ & $\begin{array}{l}\text { Upregulated } \\
\text { in attenuated } \\
\text { rabies }(87)^{h}\end{array}$ \\
\hline 69 & Beta-2 microglobulin & $B 2 m$ & 3.89 & 0.00073 & $\checkmark$ & $\checkmark$ & & & & & $\checkmark$ & $\checkmark$ \\
\hline 70 & cDNA sequence $A B 124611$ & $A B 124611$ & 3.88 & 0.00073 & & & & & & & $\checkmark$ & $\checkmark$ \\
\hline 71 & Complement component 5a receptor 1 & C5ar1 & 3.88 & 0.00073 & $\checkmark$ & & & $\checkmark$ & & & $\checkmark$ & $\checkmark$ \\
\hline 72 & Sp110 nuclear body protein & Sp110 & 3.86 & 0.00073 & & & $\checkmark$ & $\checkmark$ & & & $\checkmark$ & $\checkmark$ \\
\hline 73 & Lectin, galactose binding, soluble 3 & Lgals3 & 3.86 & 0.00073 & $\checkmark$ & & & $\checkmark$ & & $\checkmark$ & $\checkmark$ & $\checkmark$ \\
\hline 74 & Lymphocyte antigen 6 complex, locus A & Ly6a & 3.85 & 0.00073 & $\checkmark$ & & & & & $\checkmark$ & $\checkmark$ & $\checkmark$ \\
\hline 75 & $\begin{array}{l}\text { Eukaryotic translation elongation factor } 1 \text { alpha } \\
1 \text { pseudogene }\end{array}$ & Gm6548 & 3.83 & 0.00073 & & & & & & & $\checkmark$ & $\checkmark$ \\
\hline 76 & XIAP associated factor 1 & Xaf1 & 3.75 & 0.00073 & $\checkmark$ & $\checkmark$ & $\checkmark$ & $\sqrt{ }$ & & & $\checkmark$ & $\checkmark$ \\
\hline 77 & Fc receptor, lgG, low affinity Ilb & Fcgr2b & 3.73 & 0.00073 & $\checkmark$ & & $\checkmark$ & & & $\checkmark$ & $\checkmark$ & $\checkmark$ \\
\hline 78 & Complement component 4B (Childo blood group) & $c 4 b$ & 3.71 & 0.00073 & $\checkmark$ & & & & & & $\checkmark$ & $\checkmark$ \\
\hline 79 & Ubiquitin-conjugating enzyme E2L 6 & Ube2l6 & 3.71 & 0.00073 & & & & & $\checkmark$ & & $\checkmark$ & $\checkmark$ \\
\hline 80 & Interleukin 1 alpha & $\| 19 a$ & 3.62 & 0.00073 & $\checkmark$ & & & $\checkmark$ & & & $\checkmark$ & $\checkmark$ \\
\hline 81 & Chemokine (C-C motif) receptor-like 2 & Ccrl2 & 3.61 & 0.00073 & $\checkmark$ & & & & & & $\checkmark$ & $\checkmark$ \\
\hline 82 & Translocator protein & Tspo & 3.61 & 0.00073 & & & & $\checkmark$ & & & $\checkmark$ & $\checkmark$ \\
\hline 83 & Chemokine (C-X-C motif) ligand 16 & Cxcl16 & 3.60 & 0.00073 & $\checkmark$ & $\checkmark$ & & & & & $\checkmark$ & $\checkmark$ \\
\hline 84 & Cytotoxic T lymphocyte-associated protein 2 alpha & Ctla2a & 3.58 & 0.00073 & $\checkmark$ & & & & & & $\checkmark$ & $\checkmark$ \\
\hline 85 & Zinc finger protein 36 & Zfp36 & 3.57 & 0.00073 & & & $\checkmark$ & $\checkmark$ & & $\checkmark$ & $\checkmark$ & $\checkmark$ \\
\hline 86 & Tripartite motif-containing $12 \mathrm{~A}$ & $\operatorname{Trim} 12 a$ & 3.55 & 0.00073 & $\checkmark$ & & & & & & & \\
\hline 87 & Complement component 3 a receptor 1 & C3ar1 & 3.53 & 0.00073 & $\checkmark$ & & & & & $\checkmark$ & $\checkmark$ & $\checkmark$ \\
\hline 88 & Capping protein (actin filament), gelsolin-like & Capg & 3.46 & 0.00073 & & & & & & & $\checkmark$ & $\checkmark$ \\
\hline 89 & Interferon regulatory factor 1 & Irf1 & 3.45 & 0.00073 & $\checkmark$ & $\checkmark$ & $\checkmark$ & $\checkmark$ & & $\checkmark$ & $\checkmark$ & $\checkmark$ \\
\hline 90 & RAB20, member RAS oncogene family & Rab20 & 3.45 & 0.00355 & & & & & & & $\checkmark$ & \\
\hline 91 & Growth arrest and DNA-damage-inducible 45 beta & Gadd45b & 3.41 & 0.00073 & & & & $\checkmark$ & & & $\checkmark$ & \\
\hline 92 & Early growth response 2 & Egr2 & 3.41 & 0.00073 & & & & & & & $\checkmark$ & \\
\hline 93 & Epithelial stromal interaction 1 (breast) & Epsti1 & 3.39 & 0.00073 & & & & & & & $\checkmark$ & $\checkmark$ \\
\hline 94 & Intercellular adhesion molecule 1 & Icam1 & 3.39 & 0.00073 & $\checkmark$ & $\checkmark$ & $\checkmark$ & $\checkmark$ & & $\checkmark$ & $\checkmark$ & $\checkmark$ \\
\hline 95 & C-type lectin domain family 4 , member a3 & Clec $4 a 3$ & 3.37 & 0.00073 & & & & & & & $\checkmark$ & \\
\hline 96 & Cathepsin C & Ctsc & 3.36 & 0.00073 & $\checkmark$ & & & $\checkmark$ & & $\checkmark$ & $\checkmark$ & $\checkmark$ \\
\hline 97 & B-cell leukemia/lymphoma 2 related protein A1b & $B c 12 a 1 b$ & 3.33 & 0.00073 & & & & $\checkmark$ & & & & \\
\hline 98 & Heme oxygenase (decycling) 1 & Hmox1 & 3.33 & 0.00073 & $\checkmark$ & & & $\checkmark$ & & $\checkmark$ & $\checkmark$ & $\checkmark$ \\
\hline 99 & Immunoglobulin superfamily, member 6 & lgsf6 & 3.31 & 0.00073 & $\checkmark$ & & & & & & $\checkmark$ & $\checkmark$ \\
\hline 100 & Histocompatibility 2, D region locus 1 & H2-D1 & 3.29 & 0.00073 & $\checkmark$ & & & & & & $\checkmark$ & $\checkmark$ \\
\hline
\end{tabular}

Immune response (G0:0002376, G0:0006955).

${ }^{b}$ Response to interferon (G0:0060337, G0:0034341, G0:0035456, and G0:0035455).

'Defense response to virus/viral process (G0:0009615, G0:0016032).

${ }^{d}$ Apoptosis (G0:0010942, G0:0043068, G0:0043065).

eProtein ubiquitination (G0:0016567).

fupregulated in PRV-infected rats CNS (Paulus et al., 2006).

${ }^{9}$ Upregulated in virulent rabies (strain CVS-11)-infected mice (Zhang et al., 2016).

${ }^{h}$ Upregulated in attenuated rabies (strain HEP-Flury)-infected mice (Zhang et al., 2016).

injecting PRV-Introvert-GFP into the NAc of DAT-Cre mice, $\mathrm{MCH}$, HCRT, CART and GAL gene products all colocalized with GFP (Fig. $7 \mathrm{~B}, \mathrm{C})$. Since $\mathrm{MCH}$ and HCRT are two of the most prominent neural populations in $\mathrm{LH}$, these data suggest that a substantial proportion of LH neurons are presynaptic to dopamine neurons in the VTA. GFP staining was detected in neurons of the Arc, but proopiomelanocortin (POMC) showed little colocalization with GFP (Fig. $7 B, C$, POMC). In aggregate, these anatomic studies validate the use of PRV-Circuit-TRAP to identify markers for neurons identified using PRV-Introvert-GFP for neural tracing.

\section{Discussion}

Identification of multisynaptic inputs to the mesolimbic dopamine circuit with PRV-Introvert-GFP

The current study validates a novel approach for robustly mapping presynaptic inputs to defined neural populations and simultaneously molecularly profiling those neurons. The method uses an engineered version of PRV-Bartha, an anatomical tracer that serially infects neurons in a retrograde fashion (Enquist, 2002; Pickard et al., 2002; Ekstrand et al., 2008). The development of this approach required that we modify PRV-Bartha such that replication, propagation, and expression of GFP were strictly dependent on the presence of Cre recombinase in starter neurons without background expression of GFP or viral propagation in neurons that do not express Cre. As shown, the Introvert tk construct we developed provides extremely tight Credependent control of PRV replication, retrograde viral spread, and GFP expression.

Specific regions of input and output to the VTA were defined previously (Geisler and Zahm, 2005; Ikemoto, 2007) most notably in recent studies that focused specifically on the presynaptic connections of VTA DA neurons (Watabe-Uchida et al., 2012; Beier et al., 2015; Nieh et al., 2015). Our retrograde tracing studies with PRV-Introvert-GFP identified all of these known monosynaptic inputs to dopaminergic VTA neurons with the exception of the direct projections from the NAc to the VTA (Fig. 3B). One explanation for this distinction is that PRV and RV likely have different affinities for crossing synapses with a particular architecture or physiologic property (Card et al., 1999). Neurons in the NAc that send monosynaptic projections to the VTA are arranged in patches (Watabe-Uchida et al., 2012) and are much less abundant than projections from the VTA to the NAc (Oh et al., 2014). These factors may contribute to the absence of PRV tracing to monosynaptic connections from the NAc. In contrast, while neurons from the lateral hypothalamus and dorsal raphe 
Table 2. Sixty genes with greatest enrichment in afferents to the mesolimbic dopamine circuit ( $q$ values $<0.005$ )

\begin{tabular}{|c|c|c|c|c|c|c|}
\hline & Gene & Description & IP/input & $q$ value & Infected/not infected & IP/input weighted for PRV \\
\hline 1 & Slc6a4 & Serotonin transporter/SERT/5-HTT & 9.37 & 0.00067 & 0.74 & 12.73 \\
\hline 2 & Rn45s & $45 S$ preribosomal RNA & 11.76 & 0.00067 & 0.95 & 12.36 \\
\hline 3 & Gchfr & GTP cyclohydrolase I feedback regulator & 4.86 & 0.00067 & 0.47 & 10.34 \\
\hline 4 & Pmch & Pro-melanin-concentrating hormone & 5.02 & 0.00067 & 0.49 & 10.21 \\
\hline 5 & Parpbp & PARP1 binding protein/C12orf48 & 4.96 & 0.00067 & 0.55 & 9.02 \\
\hline 6 & Panx1 & Pannexin 1 & 3.61 & 0.00067 & 0.54 & 6.64 \\
\hline 7 & Cartpt & CART prepropeptide & 3.56 & 0.00067 & 0.58 & 6.19 \\
\hline 8 & Tbca & Tubulin cofactor A & 2.53 & 0.00067 & 0.43 & 5.89 \\
\hline 9 & Gm1673 & predicted gene 1673 & 3.96 & 0.00067 & 0.68 & 5.81 \\
\hline 10 & Eid2 & EP300 interacting inhibitor of differentiation 2 & 4.23 & 0.00125 & 0.75 & 5.68 \\
\hline 11 & Fbll1 & Fibrillarin-like 1 & 3.56 & 0.00067 & 0.64 & 5.55 \\
\hline 12 & Lsm4 & LSM4 homolog, U6 small nuclear RNA associated & 3.12 & 0.00067 & 0.58 & 5.41 \\
\hline 13 & $Y d j c$ & YdjC homolog (bacterial) & 3.39 & 0.00067 & 0.63 & 5.35 \\
\hline 14 & C1qtnf4 & C1q and tumor necrosis factor related protein 4 & 3.67 & 0.00067 & 0.69 & 5.33 \\
\hline 15 & Arhgdig & Rho GDP dissociation inhibitor (GDI) gamma & 3.45 & 0.00067 & 0.66 & 5.24 \\
\hline 16 & Pafah1b3 & Platelet-activating factor acetylhydrolase $1 \mathrm{~b}$, subunit & 3.26 & 0.00067 & 0.63 & 5.16 \\
\hline 17 & Ly6h & Lymphocyte antigen 6 complex, locus $\mathrm{H}$ & 4.45 & 0.00067 & 0.86 & 5.15 \\
\hline 18 & Pcbd1 & Pterin 4 alpha carbinolamine dehydratase (TCF1) 1 & 3.34 & 0.00067 & 0.66 & 5.07 \\
\hline 19 & Slc18a3 & Vesicular acetylcholine transporter/VAchT & 3.97 & 0.00180 & 0.78 & 5.07 \\
\hline 20 & Ncrna00086 & Non-protein coding RNA 86 & 2.69 & 0.00067 & 0.55 & 4.88 \\
\hline 21 & Fxyd7 & FXYD domain-containing ion transport regulator 7 & 2.79 & 0.00067 & 0.57 & 4.87 \\
\hline 22 & Vat1 & Vesicle amine transport protein 1 homolog & 3.86 & 0.00125 & 0.81 & 4.79 \\
\hline 23 & 1700037H04 & RIKEN CDNA 1700037 H04 gene & 3.16 & 0.00067 & 0.67 & 4.71 \\
\hline 24 & $0 x t$ & Oxytocin & 2.81 & 0.00067 & 0.61 & 4.57 \\
\hline 25 & Th & Tyrosine hydroxylase & 2.89 & 0.00067 & 0.63 & 4.55 \\
\hline 26 & $N d n$ & necdin & 3.11 & 0.00067 & 0.70 & 4.47 \\
\hline 27 & $2700094 K 13$ & RIKEN CDNA 2700094K13 gene & 3.13 & 0.00067 & 0.71 & 4.44 \\
\hline 28 & Grec10 & Gene rich cluster, $\mathrm{C} 10$ gene & 3.69 & 0.00067 & 0.84 & 4.42 \\
\hline 29 & Nxph4 & Neurexophilin 4 & 5.00 & 0.00067 & 1.13 & 4.41 \\
\hline 30 & Ptov1 & Prostate tumor over expressed 1 & 3.11 & 0.00067 & 0.71 & 4.40 \\
\hline 31 & $\operatorname{Lin} 7 b$ & Lin-7 homolog B (C. elegans) & 2.21 & 0.00067 & 0.51 & 4.35 \\
\hline 32 & Aldh $3 b 2$ & Aldehyde dehydrogenase 3 family, member B2 & 2.51 & 0.00067 & 0.59 & 4.25 \\
\hline 33 & Bex1 & Brain expressed gene 1 & 3.49 & 0.00067 & 0.83 & 4.19 \\
\hline 34 & Ctxn2 & Cortexin 2 & 2.91 & 0.00067 & 0.69 & 4.19 \\
\hline 35 & Sncg & Synuclein, gamma & 2.38 & 0.00067 & 0.57 & 4.16 \\
\hline 36 & Slc10a4 & Solute carrier family 10 member 4 & 3.36 & 0.00067 & 0.81 & 4.14 \\
\hline 37 & Bex4 & Brain expressed X-linked 4 & 3.13 & 0.00067 & 0.76 & 4.11 \\
\hline 38 & Rpl22/1 & Ribosomal protein L22 like 1 & 3.59 & 0.00067 & 0.87 & 4.11 \\
\hline 39 & Slirp & SRA step-loop interacting RNA binding protein & 3.97 & 0.00067 & 0.97 & 4.09 \\
\hline 40 & lgsf8 & Immunoglobulin superfamily, member 8 & 3.73 & 0.00067 & 0.92 & 4.06 \\
\hline 41 & $1700001 L 19$ & RIKEN CDNA 1700001L19 gene & 2.01 & 0.00067 & 0.49 & 4.06 \\
\hline 42 & $T t c 9 b$ & Tetratricopeptide repeat domain 9B & 4.15 & 0.00067 & 1.04 & 3.99 \\
\hline 43 & Ssscal & Sjogren's/scleroderma autoantigen 1 homolog & 2.59 & 0.00067 & 0.65 & 3.97 \\
\hline 44 & $B C 017158$ & CDNA sequence $B C 017158$ & 2.62 & 0.00067 & 0.67 & 3.94 \\
\hline 45 & Bahcc1 & BAH domain and coiled-coil containing 1 & 4.09 & 0.00067 & 1.05 & 3.91 \\
\hline 46 & Nrsn2 & Neurensin 2 & 3.26 & 0.00067 & 0.84 & 3.90 \\
\hline 47 & Rhov & Ras homolog gene family, member V & 2.97 & 0.00067 & 0.77 & 3.87 \\
\hline 48 & Tph2 & Tryptophan hydroxylase 2 & 3.13 & 0.00067 & 0.81 & 3.87 \\
\hline 49 & Ecel1 & Endothelin converting enzyme-like 1 & 3.34 & 0.00067 & 0.87 & 3.86 \\
\hline 50 & Abhd8 & Abhydrolase domain containing 8 & 3.46 & 0.00067 & 0.90 & 3.85 \\
\hline 51 & Gm12191 & Predicted gene 12191 & 3.60 & 0.00067 & 0.94 & 3.84 \\
\hline 52 & Gal & galanin & 4.16 & 0.00067 & 1.08 & 3.84 \\
\hline 53 & Psd & Pleckstrin and Sec7 domain containing & 2.80 & 0.00067 & 0.73 & 3.83 \\
\hline 54 & Lrfn3 & Leucine rich repeat and fibronectin type III & 3.00 & 0.00373 & 0.78 & 3.82 \\
\hline 55 & Hcfc1r1 & Host cell factor 11 regulator 1 (XP01-dependent) & 2.62 & 0.00067 & 0.68 & 3.82 \\
\hline 56 & Sod1 & Superoxide dismutase 1 , soluble & 3.04 & 0.00067 & 0.81 & 3.77 \\
\hline 57 & $\operatorname{Rps} 25$ & Ribosomal protein $\mathrm{S} 25$ & 3.35 & 0.00067 & 0.89 & 3.77 \\
\hline 58 & Resp18 & Regulated endocrine-specific protein 18 & 2.96 & 0.00067 & 0.79 & 3.76 \\
\hline 59 & Sema4f & Sema domain, immunoglobulin domain (lg) & 2.99 & 0.00067 & 0.79 & 3.76 \\
\hline 60 & Rnf187 & Ring finger protein 187 & 2.82 & 0.00067 & 0.75 & 3.75 \\
\hline
\end{tabular}

were shown previously to project to the VTA, and confirmed here, we also identified inputs from the piriform cortex and arcuate nucleus that were not labeled in monosynaptic tracing studies and likely represent polysynaptic connections to the VTA.
In addition to mapping inputs to the mesolimbic dopamine pathway, we produced isogenic strains of Cre-conditional PRV each expressing different fluorophores. These were used to map two circuits in the same animal, as shown in the comparison 
A

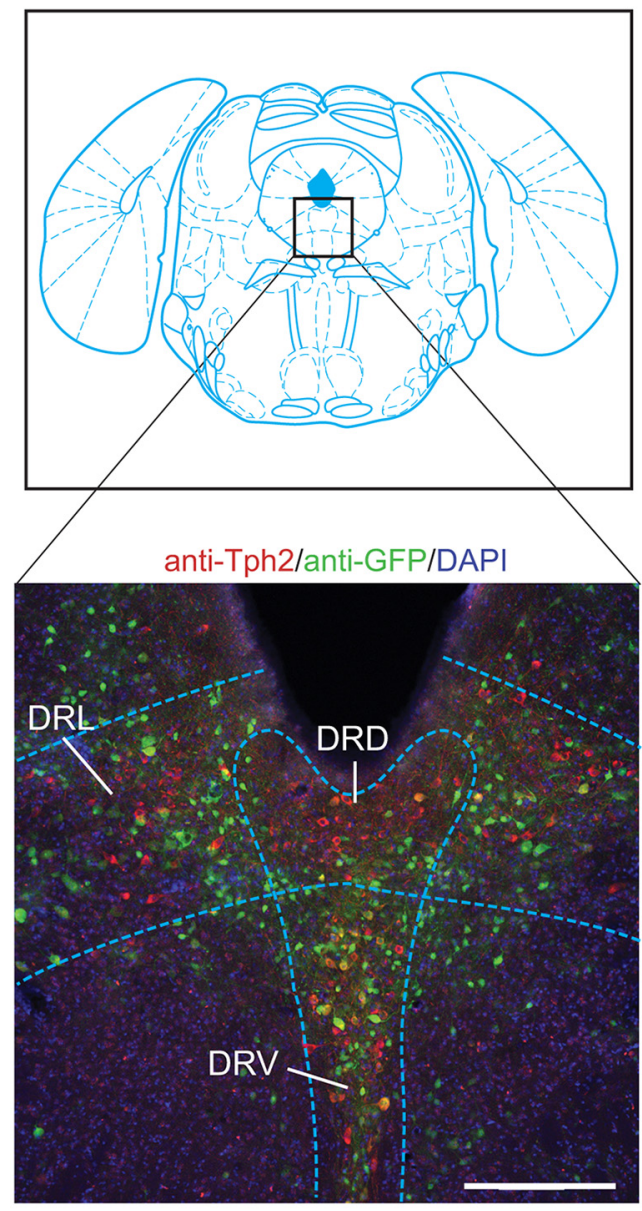

B
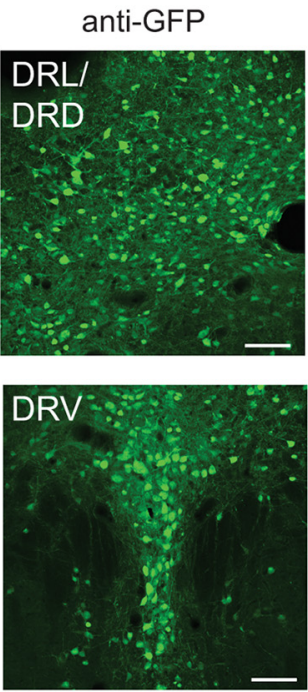

C

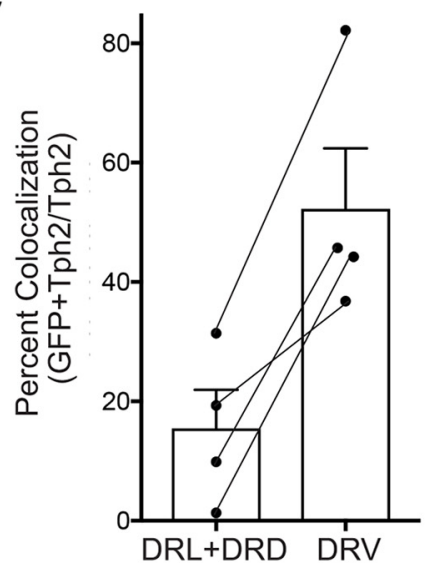

anti-Tph2
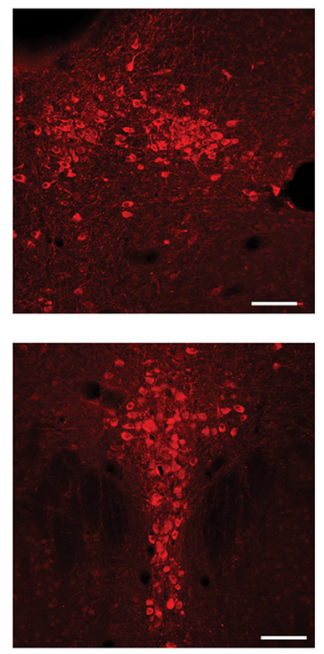

merge with DAPI
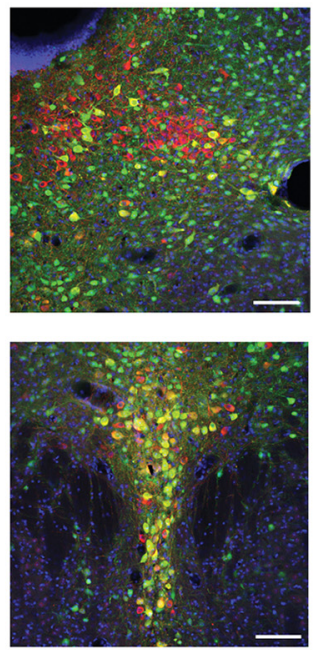

D

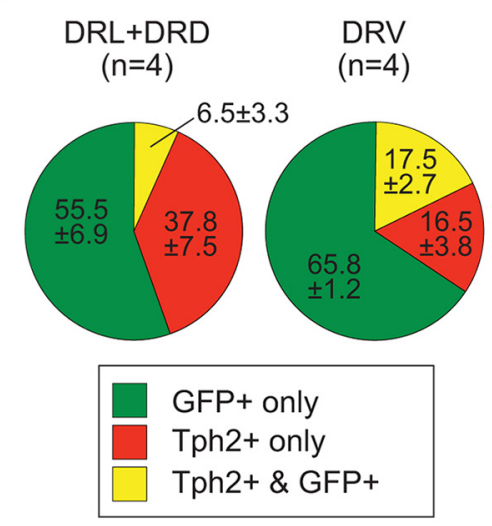

Figure 6. Serotonergic effectors of mesolimbic dopamine neurons. $\boldsymbol{A}$, Coronal section showing Bregma -4.72 (Franklin and Paxinos, 2008) and section of infected CNS tissue indicating the dorsomedial, ventromedial, and dorsolateral wings of the dorsal raphe. The section is stained with anti-Tph2, anti-GFP, and DAPI. $\boldsymbol{B}$, High-magnification images of DRL/DRD and DRV. $\boldsymbol{C}$, Percent colocalization (ratio of the number of cells in the DRN stained with both Tph2 and GFP to the number stained with Tph2 only). Error bars indicate SEM. $\boldsymbol{D}$, Quantification of cells in the DRN stained with Tph2 only, GFP only, or both Tph2 and GFP. Scale bars: $\boldsymbol{A}, 250 \mu \mathrm{m} ; \boldsymbol{B}, 100 \mu \mathrm{m}$.

between the $\mathrm{SN}^{\mathrm{DAT}} \rightarrow \mathrm{CPu}$ and $\mathrm{VTA}^{\mathrm{DAT}} \rightarrow \mathrm{NAc}$ circuitry using PRV-Introvert-GFP and PRV-Introvert-mCherry (Fig. 4). These data show almost no overlap between the inputs to these distinct circuits despite the fact that these circuits are adjacent to one another. Moreover, in some cases neurons in the same upstream nucleus were found to project to one or the other circuit but not both. These data further support the conclusion that PRV is propagated across synapses without lateral spread.

The tracing viruses we developed confer a distinct set of characteristics and are thus complementary to other available single and dual tracing methodologies using HSV or RV strains expressing different reporter proteins (Levatte et al., 1998; Ohara et al., 2009b; Lammel et al., 2012; for review, see Enquist and Card, 2003; Ohara et al., 2009a,b; Lammel et al., 2012). Similar to the recently reported TRIO approach, the use of PRV to infect terminals enables the systematic mapping of inputs to specific neural circuits (Beier et al., 2015; Lerner et al., 2015; Schwarz et al., 2015). However, the PRVassisted dual tracing method reported here differs from TRIO and other approaches in that it allows the delineation of polysynaptic circuits. While our approach does not differentiate monosynaptic from multisynaptic afferents, this system has the benefit of activation and signal amplification subsequent to viral replication in Cre- expressing neurons, permitting the direct comparison of two genetically defined, multisynaptic circuits in the same animal. Retrograde tracing with PRV-Introvert is therefore complementary to TRIO in that it allows the identification of polysynaptic inputs to defined neurons while TRIO enables the identification of first order presynaptic neurons (Beier et al., 2015; Schwarz et al., 2015).

\section{PRV-Circuit-TRAP is a tool for combined neuroanatomical mapping and molecular profiling}

In addition to transsynaptic tracing of synaptically linked neurons, PRV-Introvert-GFP enables the molecular identification of the traced neurons. In a previous study, we used CAV-GFP to profile neurons based on their pattern of projections (Ekstrand et al., 2014). In the current study, we adapted this method to profile presynaptic inputs to the $\mathrm{VTA}^{\mathrm{DAT}} \rightarrow \mathrm{NAc}$ circuit. The neuroanatomical mapping data we report using PRV-Introvert-GFP identified an extensive number of CNS structures that project to the VTA (Fig. 3B). Based on the high degree of retrograde tracing, the LH, DRN, BNST, and LHb likely represent hubs of polysynaptic input to the mesolimbic dopamine circuit. We chose to molecularly profile synaptic input arising from the LH and the DRN first because of the availability of a well-validated set of reagents for neurons in these regions. PRV- 
A
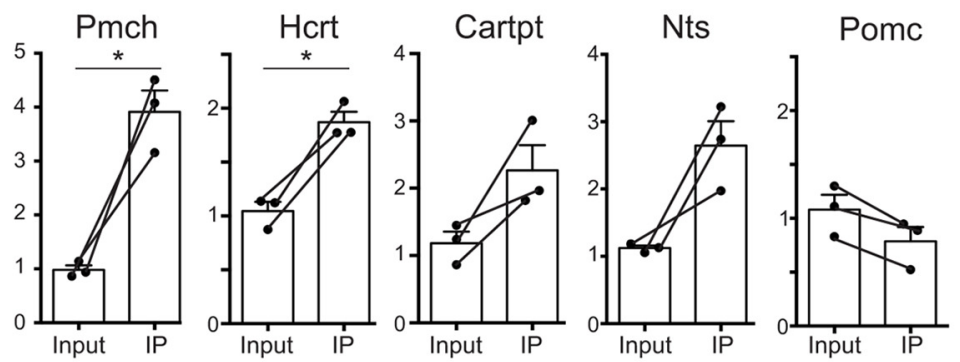

B
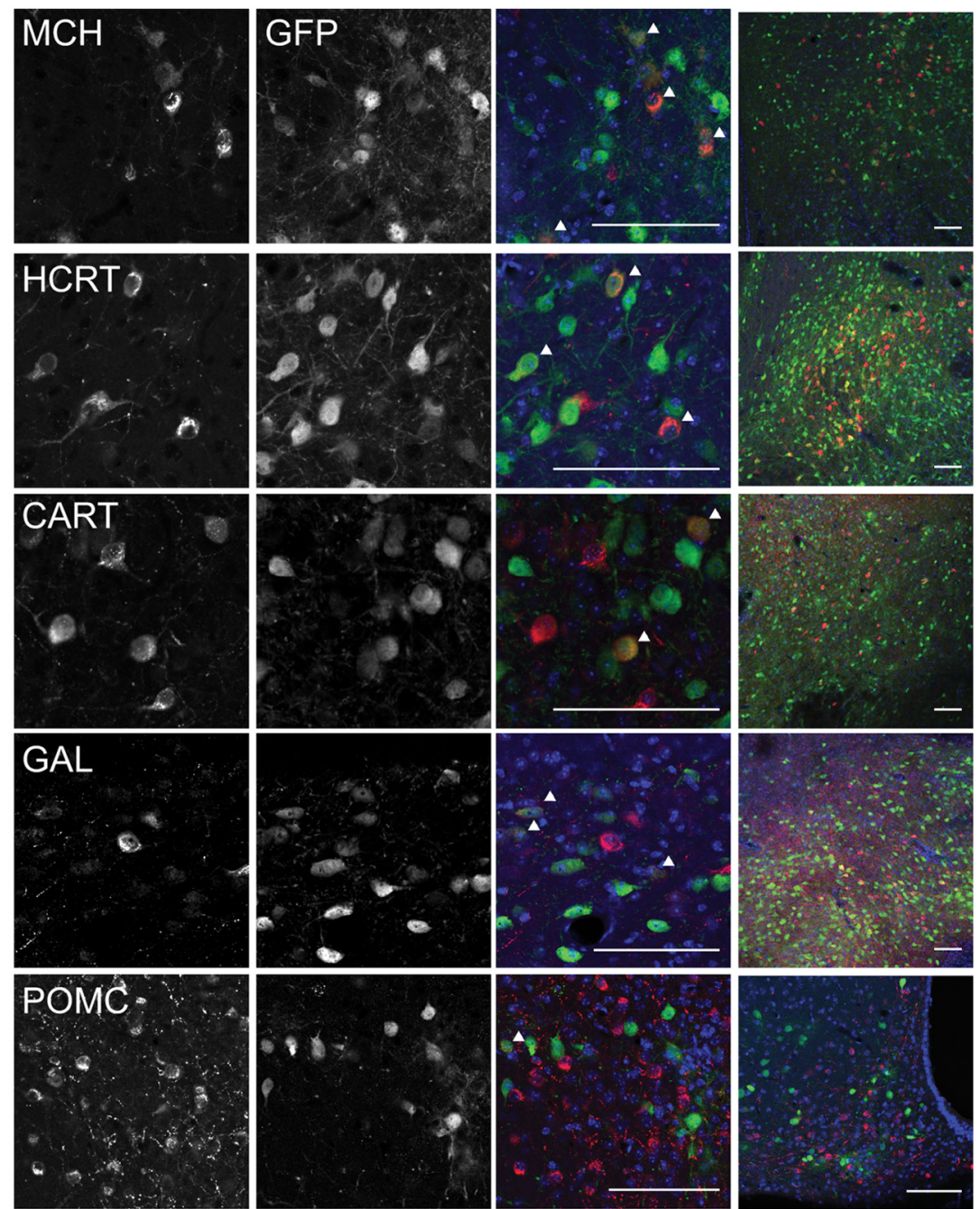

C

Percent Colocalization

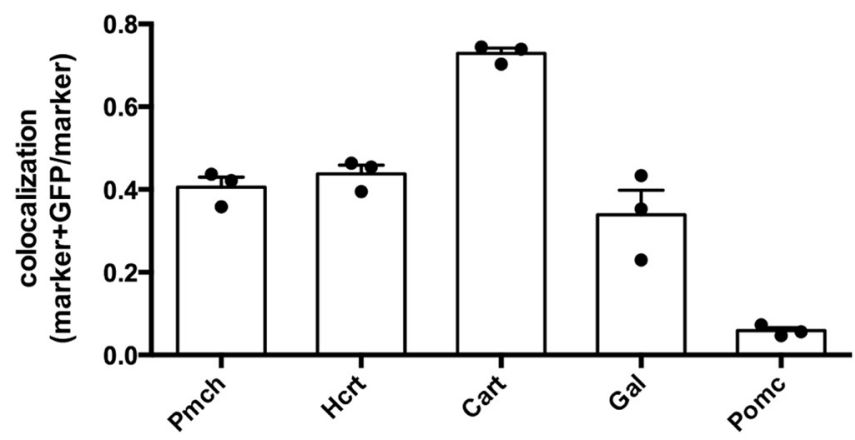

Figure 7. Hypothalamic effectors of mesolimbic dopamine neurons express appetitive markers. $A, q P C R$ of IP and input samples from PRV-Circuit-TRAP.Pmch $(p=0.024)$ and $\operatorname{Hcrt}(p=0.0134)$ RNA were significantly increased in IP compared with input samples. Cart $(p=0.0981)$, Nts $(p=0.0627)$, and Pomc $(p=0.054)$ IP and input RNA are not significantly different.
Circuit-TRAP is a high-throughput approach to molecular circuit mapping; however, the resulting connectivity profile can be expanded by focusing on neurons that express less abundant markers enriched in our IP and using more sensitive mapping techniques such as electrophysiology or single-cell RNA sequencing (Romanov et al., 2017). Furthermore, now that the method has been validated, the same approach can be used to profile neurons in other brain regions. In these studies, the circuit profiled was defined by genetics (DAT), projection site (NAc/mesolimbic), and the area chosen for dissection (midbrain). These parameters can be altered such that other circuits could be profiled by changing any one of these variables.

Profiling the traced neurons required that we correct for the effects of PRV infection on host cell gene expression. PRV infection exerts a number of well-characterized effects on cellular transcription (Szpara et al., 2010; Harkness et al., 2014). We corrected for the effect of viral infection on gene expression by weighting the average enrichment for each gene with the differential effect of PRV infection on the expression of the gene in neurons. We found that the genes that were enriched after PRV infection could be grouped into specific functional subgroups that are consistent with viral infection. Immune and stress response genes are the most highly upregulated transcripts in PRV-infected CNS tissue (Table 1), and the majority of these genes are also upregulated in rabies-infected brain tissue (Zhang et al., 2016). Furthermore, genes listed in Table 1 should not be used as neuronal markers for molecular profiling with PRVCircuit-TRAP as their expression is highly responsive to viral infection.

\section{Serotonergic and nonserotonergic projections to the VTA}

Our findings also add novel anatomic data consistent with a proposed role for a DRN projection to VTA DA neurons in reward (for review, see Luo et al., 2015). Indeed, previous studies identified the DRN as a major source of presynaptic inputs to the $\mathrm{VTA}^{\mathrm{DAT}} \rightarrow \mathrm{NAc}$ circuitry (WatabeUchida et al., 2012; McDevitt et al., 2014; Ogawa et al., 2014; Beier et al., 2015).

B, Immunohistochemistry of neuronal markers and GFP in PRV-Introvert-GFP-infected CNS. Arrowheads indicate cells stained with both marker and GFP. Scale bars, $100 \mu \mathrm{m}$. C, Quantification of PRV-Introvert-GFP colocalization with appetitive markers shown as number of neurons coexpressing marker and GFP out of the total number of marker-expressing neurons. Percentages are shown as \pm SEM. ${ }^{*} p<0.05$. 
However, tracing with PRV-Introvert-GFP revealed that only a relatively small fraction of $\mathrm{DRN} \rightarrow \mathrm{VTA}^{\mathrm{DAT}} \rightarrow \mathrm{NAc}$ neurons express the serotonergic marker Tph2 and that these cells are primarily located in the ventral portion of the DRN (DRV). Thus, although this group of Tph $2+/ \mathrm{PRV}+$ neurons represents a small portion of our total input sample, high enrichment of Sert and Tph2 messages in our IP sample (Table 2) reflect the high level of serotonin expression in these neurons. Although the DRN is characterized by a high concentration of serotonergic neurons, nonserotonergic neurons expressing dopaminergic, glutamatergic, GABergic, and nitrergic markers can also be found in this nucleus (Hioki et al., 2010; Vasudeva et al., 2011). Indeed, the results presented in Figure 6 indicate that the majority of DRN$\mathrm{VTA}^{\mathrm{DAT}} \rightarrow$ NAc neurons are nonserotonergic and could include second order interneurons or a previously characterized population of DRN glutamatergic neurons that increase the firing rate of VTA DA neurons (McDevitt et al., 2014).

\section{The profile of neurons in the $\mathrm{LH}$ that project to the mesolimbic circuit}

The LH is composed of a molecularly heterogeneous group of neurons that project broadly throughout the CNS. The circuit TRAP data suggested that multiple populations in the $\mathrm{LH}$ project to the $\mathrm{VTA}^{\mathrm{DAT}} \rightarrow \mathrm{NAc}$ circuit, and this was confirmed for Mch, Hcrt, Gal, and Cart neurons. Consistent with this anatomic data, several recent reports showed an effect of $\mathrm{MCH}$ and HCRT on the reward value of food and drugs of addiction, and these findings are consistent with our data (Counts et al., 2002; Philpot et al., 2005; Domingos et al., 2013; Beier et al., 2015; Prince et al., 2015). Consistent with findings of Pandit et al. (2016) that there are few POMC projections to $\mathrm{TH}+$ neurons in the VTA, we did not see enrichment of POMC in the profiling data.

In summary, used a set of new PRV recombinants for mapping and profiling of neurons in complex neural circuits and applied them to study projections to the mesolimbic dopamine system. The method is general and can now be used to study the anatomic and molecular components of other complex neural circuits.

\section{References}

Anthony TE, Dee N, Bernard A, Lerchner W, Heintz N, Anderson DJ (2014) Control of stress-induced persistent anxiety by an extra-amygdala septohypothalamic circuit. Cell 156:522-536. CrossRef Medline

Ashburner M, Ball CA, Blake JA, Botstein D, Butler H, Cherry JM, Davis AP, Dolinski K, Dwight SS, Eppig JT, Harris MA, Hill DP, Issel-Tarver L, Kasarskis A, Lewis S, Matese JC, Richardson JE, Ringwald M, Rubin GM, Sherlock G (2000) Gene ontology: tool for the unification of biology. The Gene Ontology Consortium. Nat Genet 25:25-29. CrossRef Medline

Banfield BW, Kaufman JD, Randall JA, Pickard GE (2003) Development of pseudorabies virus strains expressing red fluorescent proteins: new tools for multisynaptic labeling applications. J Virol 77:10106-10112. CrossRef Medline

Beier KT, Saunders A, Oldenburg IA, Miyamichi K, Akhtar N, Luo L, Whelan SP, Sabatini B, Cepko CL (2011) Anterograde or retrograde transsynaptic labeling of CNS neurons with vesicular stomatitis virus vectors. Proc Natl Acad Sci U S A 108:15414-15419. CrossRef Medline

Beier KT, Borghuis BG, El-Danaf RN, Huberman AD, Demb JB, Cepko CL (2013) Transsynaptic tracing with vesicular stomatitis virus reveals novel retinal circuitry. J Neurosci 33:35-51. CrossRef Medline

Beier KT, Steinberg EE, DeLoach KE, Xie S, Miyamichi K, Schwarz L, Gao XJ, Kremer EJ, Malenka RC, Luo L (2015) Circuit architecture of VTA dopamine neurons revealed by systematic input-output mapping. Cell 162: 622-634. CrossRef Medline

Braz JM, Enquist LW, Basbaum AI (2009) Inputs to serotonergic neurons revealed by conditional viral transneuronal tracing. J Comp Neurol 514: 145-160. CrossRef Medline

Campbell RE, Herbison AE (2007) Definition of brainstem afferents to gonadotropin-releasing hormone neurons in the mouse using conditional viral tract tracing. Endocrinology 148:5884-5890. CrossRef Medline
Cano G, Card JP, Sved AF (2004) Dual viral transneuronal tracing of central autonomic circuits involved in the innervation of the two kidneys in rat. J Comp Neurol 471:462-481. CrossRef Medline

Card JP, Enquist LW (2014) Transneuronal circuit analysis with pseudorabies viruses. Curr Protoc Neurosci 68:1.5.1-1.5.39. Medline

Card JP, Enquist LW, Moore RY (1999) Neuroinvasiveness of pseudorabies virus injected intracerebrally is dependent on viral concentration and terminal field density. J Comp Neurol 407:438-452. CrossRef Medline

Card JP, Kobiler O, Ludmir EB, Desai V, Sved AF, Enquist LW (2011) A dual infection pseudorabies virus conditional reporter approach to identify projections to collateralized neurons in complex neural circuits. PLoS One 6:e21141. CrossRef Medline

Chaudhury D, Walsh JJ, Friedman AK, Juarez B, Ku SM, Koo JW, Ferguson D, Tsai HC, Pomeranz LE, Christoffel DJ, Nectow AR, Ekstrand M, Domingos A, Mazei-Robison MS, Mouzon E, Lobo MK, Neve RL, Friedman JM, Russo SJ, Deisseroth K, Nestler EJ, Han MH (2013) Rapid regulation of depression-related behaviours by control of midbrain dopamine neurons. Nature 493:532-536. Medline

Counts SE, McGuire SO, Sortwell CE, Crawley JN, Collier TJ, Mufson EJ (2002) Galanin inhibits tyrosine hydroxylase expression in midbrain dopaminergic neurons. J of neurochemistry 83:442-451. CrossRef

DeFalco J, Tomishima M, Liu H, Zhao C, Cai X, Marth JD, Enquist L, Friedman JM (2001) Virus-assisted mapping of neural inputs to a feeding center in the hypothalamus. Science 291:2608-2613. CrossRef Medline

Domingos AI, Sordillo A, Dietrich MO, Liu ZW, Tellez LA, Vaynshteyn J, Ferreira JG, Ekstrand MI, Horvath TL, de Araujo IE, Friedman JM (2013) Hypothalamic melanin concentrating hormone neurons communicate the nutrient value of sugar. Elife 2:e01462. Medline

Donnelly ML, Hughes LE, Luke G, Mendoza H, ten Dam E, Gani D, Ryan MD (2001) The 'cleavage' activities of foot-and-mouth disease virus 2A sitedirected mutants and naturally occurring '2A-like' sequences. J Gen Virol 82:1027-1041. CrossRef Medline

Doyle JP, Dougherty JD, Heiman M, Schmidt EF, Stevens TR, Ma G, Bupp S, Shrestha P, Shah RD, Doughty ML, Gong S, Greengard P, Heintz N (2008) Application of a translational profiling approach for the comparative analysis of CNS cell types. Cell 135:749-762. CrossRef Medline

Dunnett SB (2005) Dopamine, Ed 1. Amsterdam: Elsevier.

Ekstrand MI, Terzioglu M, Galter D, Zhu S, Hofstetter C, Lindqvist E, Thams S, Bergstrand A, Hansson FS, Trifunovic A, Hoffer B, Cullheim S, Mohammed AH, Olson L, Larsson NG (2007) Progressive parkinsonism in mice with respiratory-chain-deficient dopamine neurons. Proc Natl Acad Sci U S A 104:1325-1330. CrossRef Medline

Ekstrand MI, Enquist LW, Pomeranz LE (2008) The alpha-herpesviruses: molecular pathfinders in nervous system circuits. Trends Mol Med 14: 134-140. CrossRef Medline

Ekstrand MI, Nectow AR, Knight ZA, Latcha KN, Pomeranz LE, Friedman JM (2014) Molecular profiling of neurons based on connectivity. Cell 157:1230-1242. CrossRef Medline

Enquist LW (2002) Exploiting circuit-specific spread of pseudorabies virus in the central nervous system: insights to pathogenesis and circuit tracers. J Infect Dis 186 Suppl 2:S209-214.

Enquist LW, Card JP (2003) Recent advances in the use of neurotropic viruses for circuit analysis. Curr Opin Neurobiol 13:603-606. CrossRef Medline

Flori L, Rogel-Gaillard C, Cochet M, Lemonnier G, Hugot K, Chardon P, Robin S, Lefèvre F (2008) Transcriptomic analysis of the dialogue between pseudorabies virus and porcine epithelial cells during infection. BMC Genomics 9:123. CrossRef Medline

Franklin KBJ, Paxinos G (2008) The mouse brain in stereotaxic coordinates, Ed 3. Amsterdam: Elsevier.

Geisler S, Zahm DS (2005) Afferents of the ventral tegmental area in the rat-anatomical substratum for integrative functions. J Comp Neurol 490: 270-294. CrossRef Medline

Gene Ontology Consortium (2015) Gene Ontology Consortium: going forward. Nucleic Acids Res 43:D1049-D1056. CrossRef Medline

Gentry GA, Aswell JF (1975) Inhibition of herpes simplex virus replication by araT. Virology 65:294-296. CrossRef Medline

Harkness JM, Kader M, DeLuca NA (2014) Transcription of the herpes simplex virus 1 genome during productive and quiescent infection of neuronal and nonneuronal cells. J Virol 88:6847-6861. CrossRef Medline

Hioki H, Nakamura H, Ma YF, Konno M, Hayakawa T, Nakamura KC, Fujiyama F, Kaneko T (2010) Vesicular glutamate transporter 3-expressing nonserotoner- 
gic projection neurons constitute a subregion in the rat midbrain raphe nuclei. J Comp Neurol 518:668-686. CrossRef Medline

Hu B, Li X, Huo Y, Yu Y, Zhang Q, Chen G, Zhang Y, Fraser NW, Wu D, Zhou J (2016) Cellular responses to HSV-1 infection are linked to specific types of alterations in the host transcriptome. Sci Rep 6:28075. CrossRef Medline

Ikemoto S (2007) Dopamine reward circuitry: two projection systems from the ventral midbrain to the nucleus accumbens-olfactory tubercle complex. Brain Res Rev 56:27-78. CrossRef Medline

Jansen AS, Nguyen XV, Karpitskiy V, Mettenleiter TC, Loewy AD (1995) Central command neurons of the sympathetic nervous system: basis of the fight-or-flight response. Science 270:644-646. CrossRef Medline

Kelly RM, Strick PL (2000) Rabies as a transneuronal tracer of circuits in the central nervous system. J Neurosci Methods 103:63-71. CrossRef Medline

Kobiler O, Lipman Y, Therkelsen K, Daubechies I, Enquist LW (2010) Herpesviruses carrying a Brainbow cassette reveal replication and expression of limited numbers of incoming genomes. Nat Commun 1:146. CrossRef Medline

Lammel S, Lim BK, Ran C, Huang KW, Betley MJ, Tye KM, Deisseroth K, Malenka RC (2012) Input-specific control of reward and aversion in the ventral tegmental area. Nature 491:212-217. CrossRef Medline

Lammel S, Steinberg EE, Földy C, Wall NR, Beier K, Luo L, Malenka RC (2015) Diversity of transgenic mouse models for selective targeting of midbrain dopamine neurons. Neuron 85:429-438. CrossRef Medline

Lanciego JL, Wouterlood FG (2011) A half century of experimental neuroanatomical tracing. J Chem Neuroanat 42:157-183. CrossRef Medline

Lein ES, Hawrylycz MJ, Ao N, Ayres M, Bensinger A, Bernard A, Boe AF, Boguski MS, Brockway KS, Byrnes EJ, Chen L, Chen L, Chen TM, Chin MC, Chong J, Crook BE, Czaplinska A, Dang CN, Datta S, Dee NR, et al. (2007) Genome-wide atlas of gene expression in the adult mouse brain. Nature 445:168-176. CrossRef Medline

Lerner TN, Shilyansky C, Davidson TJ, Evans KE, Beier KT, Zalocusky KA, Crow AK, Malenka RC, Luo L, Tomer R, Deisseroth K (2015) Intactbrain analyses reveal distinct information carried by SNc dopamine subcircuits. Cell 162:635-647. CrossRef Medline

Levatte MA, Mabon PJ, Weaver LC, Dekaban GA (1998) Simultaneous identification of two populations of sympathetic preganglionic neurons using recombinant herpes simplex virus type 1 expressing different reporter genes. Neuroscience 82:1253-1267. Medline

Lo L, Anderson DJ (2011) A Cre-dependent, anterograde transsynaptic viral tracer for mapping output pathways of genetically marked neurons. Neuron 72:938-950. CrossRef Medline

Luo M, Zhou J, Liu Z (2015) Reward processing by the dorsal raphe nucleus: 5-HT and beyond. Learn Mem 22:452-460. CrossRef Medline

McDevitt RA, Tiran-Cappello A, Shen H, Balderas I, Britt JP, Marino RA, Chung SL, Richie CT, Harvey BK, Bonci A (2014) Serotonergic versus nonserotonergic dorsal raphe projection neurons: differential participation in reward circuitry. Cell Rep 8:1857-1869. CrossRef Medline

Mundell NA, Beier KT, Pan YA, Lapan SW, Göz Aytürk D, Berezovskii VK, Wark AR, Drokhlyansky E, Bielecki J, Born RT, Schier AF, Cepko CL (2015) Vesicular stomatitis virus enables gene transfer and transsynaptic tracing in a wide range of organisms. J Comp Neurol 523:1639-1663. CrossRef Medline

Nectow AR, Ekstrand MI, Friedman JM (2015) Molecular characterization of neuronal cell types based on patterns of projection with Retro-TRAP. Nat Protoc 10:1319-1327. CrossRef Medline

Nieh EH, Matthews GA, Allsop SA, Presbrey KN, Leppla CA, Wichmann R, Neve R, Wildes CP, Tye KM (2015) Decoding neural circuits that control compulsive sucrose seeking. Cell 160:528-541. CrossRef Medline

Ogawa SK, Cohen JY, Hwang D, Uchida N, Watabe-Uchida M (2014) Organization of monosynaptic inputs to the serotonin and dopamine neuromodulatory systems. Cell Rep 8:1105-1118. CrossRef Medline

Oh SW, Harris JA, Ng L, Winslow B, Cain N, Mihalas S, Wang Q, Lau C, Kuan L, Henry AM, Mortrud MT, Ouellette B, Nguyen TN, Sorensen SA, Slaughterbeck CR, Wakeman W, Li Y, Feng D, Ho A, Nicholas E, et al. (2014) A mesoscale connectome of the mouse brain. Nature 508:207214. CrossRef Medline

Ohara S, Inoue K, Witter MP, Iijima T (2009a) Untangling neural networks with dual retrograde transsynaptic viral infection. Front Neurosci 3:344349. CrossRef Medline

Ohara S, Inoue K, Yamada M, Yamawaki T, Koganezawa N, Tsutsui K, Witter MP, Iijima T (2009b) Dual transneuronal tracing in the rat entorhinal- hippocampal circuit by intracerebral injection of recombinant rabies virus vectors. Front Neuroanat 3:1. Medline

Oláh P, Tombácz D, Póka N, Csabai Z, Prazsák I, Boldogkői Z (2015) Characterization of pseudorabies virus transcriptome by Illumina sequencing. BMC Microbiol 15:130. CrossRef Medline

Pandit R, Omrani A, Luijendijk MC, de Vrind VA, Van Rozen AJ, Ophuis RJ, Garner K, Kallo I, Ghanem A, Liposits Z, Conzelmann KK, Vanderschuren LJ, la Fleur SE, Adan RA (2016) Melanocortin 3 receptor signaling in midbrain dopamine neurons increases the motivation for food reward. Neuropsychopharmacology 41:2241-2251. CrossRef Medline

Paulus C, Sollars PJ, Pickard GE, Enquist LW (2006) Transcriptome signature of virulent and attenuated pseudorabies virus-infected rodent brain. J Virol 80:1773-1786. CrossRef Medline

Philpot KB, Dallvechia-Adams S, Smith Y, Kuhar MJ (2005) A cocaine-andamphetamine-regulated-transcript peptide projection from the lateral hypothalamus to the ventral tegmental area. Neuroscience 135:915-925. CrossRef Medline

Pickard GE, Smeraski CA, Tomlinson CC, Banfield BW, Kaufman J, Wilcox CL, Enquist LW, Sollars PJ (2002) Intravitreal injection of the attenuated pseudorabies virus PRV Bartha results in infection of the hamster suprachiasmatic nucleus only by retrograde transsynaptic transport via autonomic circuits. J Neurosci 22:2701-2710. Medline

Pomeranz LE, Reynolds AE, Hengartner CJ (2005) Molecular biology of pseudorabies virus: impact on neurovirology and veterinary medicine. Microbiol Mol Biol Rev 69:462-500. CrossRef Medline

Prince CD, Rau AR, Yorgason JT, España RA (2015) Hypocretin/Orexin regulation of dopamine signaling and cocaine self-administration is mediated predominantly by hypocretin receptor 1 . ACS Chem Neurosci 6:138-146. CrossRef Medline

Ray N, Enquist LW (2004) Transcriptional response of a common permissive cell type to infection by two diverse alphaherpesviruses. J Virol 78: 3489-3501. CrossRef Medline

Romanov RA, Alpár A, Hökfelt T, Harkany T (2017) Molecular diversity of corticotropin-releasing hormone mRNA-containing neurons in the hypothalamus. J Endocrinol 232:R161-R172. CrossRef Medline

Schwarz LA, Miyamichi K, Gao XJ, Beier KT, Weissbourd B, DeLoach KE, Ren J, Ibanes S, Malenka RC, Kremer EJ, Luo L (2015) Viral-genetic tracing of the input-output organization of a central noradrenaline circuit. Nature 524:88-92. CrossRef Medline

Smith GA, Enquist LW (2000) A self-recombining bacterial artificial chromosome and its application for analysis of herpesvirus pathogenesis. Proc Natl Acad Sci U S A 97:4873-4878. CrossRef Medline

Szpara ML, Kobiler O, Enquist LW (2010) A common neuronal response to alphaherpesvirus infection. J Neuroimmune Pharmacol 5:418-427. CrossRef Medline

Trapnell C, Hendrickson DG, Sauvageau M, Goff L, Rinn JL, Pachter L (2013) Differential analysis of gene regulation at transcript resolution with RNA-seq. Nat Biotechnol 31:46-53. Medline

Ugolini G (2011) Rabies virus as a transneuronal tracer of neuronal connections. Adv Virus Res 79:165-202. CrossRef Medline

Vasudeva RK, Lin RC, Simpson KL, Waterhouse BD (2011) Functional organization of the dorsal raphe efferent system with special consideration of nitrergic cell groups. J Chem Neuroanat 41:281-293. CrossRef Medline

Warming S, Costantino N, Court DL, Jenkins NA, Copeland NG (2005) Simple and highly efficient BAC recombineering using galK selection. Nucleic Acids Res 33:e36. CrossRef Medline

Watabe-Uchida M, Zhu L, Ogawa SK, Vamanrao A, Uchida N (2012) Whole-brain mapping of direct inputs to midbrain dopamine neurons. Neuron 74:858-873. CrossRef Medline

Wickersham IR, Finke S, Conzelmann KK, Callaway EM (2007a) Retrograde neuronal tracing with a deletion-mutant rabies virus. Nat Methods 4:47-49. CrossRef Medline

Wickersham IR, Lyon DC, Barnard RJ, Mori T, Finke S, Conzelmann KK, Young JA, Callaway EM (2007b) Monosynaptic restriction of transsynaptic tracing from single, genetically targeted neurons. Neuron 53:639647. CrossRef Medline

Yoon H, Enquist LW, Dulac C (2005) Olfactory inputs to hypothalamic neurons controlling reproduction and fertility. Cell 123:669-682. CrossRef Medline

Zhang D, He F, Bi S, Guo H, Zhang B, Wu F, Liang J, Yang Y, Tian Q, Ju C, Fan H, Chen J, Guo X, Luo Y (2016) Genome-wide transcriptional profiling reveals two distinct outcomes in central nervous system infections of rabies virus. Front Microbiol 7:751. Medline 